\title{
4. Klepper, der Präsident der Preußenkasse, und sein agrarpolitisches Programm
}

Ministerpräsident Otto Braun hatte „besonders deshalb Wert auf Kleppers Berufung gelegt, weil er mit Recht der weitgehend auf undurchsichtiger Protektion und verwandtschaftlichen Beziehungen beruhenden Verschuldung der ostdeutschen Genossenschaften, in denen die Güter führend waren, ein Ende machen wollte und hoffte, daß Klepper hierfür der richtige Mann wäre “'. Der für die Preußenkasse zuständige Finanzminister Höpker-Aschoff hatte sich, wie er vor dem Landtag betonte, „sehr sorgfältig auch in Bankkreisen und bei allen möglichen Stellen über die Qualifikation des Herrn Klepper erkundigt und über ihn nur Gutes gehört“, er habe „die Domänenbank aufgebaut und gut geleitet. Eine jüngst vorgenommene Revision bei der Domänenbank “ habe nicht nur „ein durchaus günstiges Ergebnis gehabt“, sondern bewiesen, „daß in der ganzen Geschäftsgebarung der Domänenbank eine ausgezeichnete Übersicht und Klarheit herrsche, - also gerade das, was wir bei der Preußenkasse so überaus schmerzlich vermissen müssen“2. Klepper war, wie er seinem ehemaligen Corpsbruder nach dem Kriege gestand, an Sempers „Sturz nicht unbeteiligt“, wobei er fairerweise hinzufügte: „Ich kann ihm also nicht verübeln, daß er sich nicht zu meinen Freunden zählt. ${ }^{3}$ Topf sagt, Klepper sei „dank einer von ihm mit außerordentlichem Geschick angelegten und geführten Kampagne, in das Haus ,Hinterm Zeughaus', und damit in eine der wichtigsten Positio-

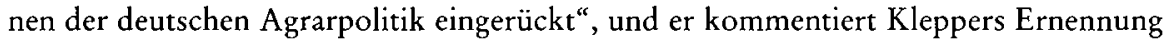
in seinem Artikel „Der Napoleon der P.Z.“ mit dem Satz: „Napoleon geht an die Front und übernimmt den Befehl." 4

Wie nicht anders zu erwarten, erhob sich auf der Rechten, sowohl im Landtag wie in der Presse, ein Sturm der Entrüstung. Man sprach vom „Kompromiß auf dem Rücken der Wirtschaft", vom „besonderen Beschluß und intriguenhaft durchgesetzten Stück neupreußischer Wirtschaftspolitik“ ${ }^{5}$ und vom „Entgegenkommen“ gegenüber den „Linksparteien"6. Man befürchtete, die „bäuerlichen Genossen [würden] der Zwangsbewirtschaftung öffentlicher Gelder nach parteipolitischer Schablone" unterworfen, und die „Betriebskontrolle“ werde die "Selbstverantwortung" ausschalten ${ }^{7}$, deshalb bringe man „Klepper in allen Kreisen des deutschen Genossenschaftswesens ein weitgehendes Mißtrauen entgegen"8. So wurden politische, aus Angst vor Veränderungen und aus mangelhaften Informationen über seine vorherige Tätigkeit für die Domänenpächter gespeiste Vorwürfe erhoben, und die Entscheidung für Klepper wurde parteipolitisch in-

\footnotetext{
${ }^{1}$ Boyens, Bd. II, S. 173.

2 PrLT, 366. Sitzung, Sp. 26094.

${ }^{3}$ Klepper an Georg Braun, 19. 6. 1951 (K/Kor.).

4 Topf, S. 90 und Topf, Napoleon, S. 467.

5 Tägliche Rundschau, 16. 1. 1928.

6 Deutsche Tageszeitung, 13. 1. 1928.

7 Hermann Hillger-Spiegelberg (DNVP) in PrLT, 366. Sitzung, 26. 3. 1928, Sp. 26093 und 26091.

${ }^{8}$ Ebenda, Eugen Leidig (DVP), Sp. 26106.
} 
terpretiert ${ }^{9}$, obwohl das Berliner Tageblatt gerade die "unpolitische Entscheidung " für einen "politisch nicht irgendwie festgelegten Fachmann" unterstrich ${ }^{10}$.

Wie unberechtigt die Vorwürfe der Rechtspresse gegen Kleppers Tätigkeit als Vorsitzender des Domänenpächterverbandes und der Domänenbank waren, zeigt der scharfe Protest von Bernhard v. Bernuth, der allen Grund gehabt hätte, Klepper wegen seines Weggangs zu grollen: „Ich bedaure die Stellungnahme der Deutschen Tageszeitung gegenüber Herrn Klepper lebhaft, zumal ich das gefällte Urteil über seine Tätigkeit bei der Domänenbank für durchaus verfehlt halte. Aus einem Nichts ist die Domänenbank zu einer sehr segensreichen Einrichtung zunächst für die preußischen Domänenpächter, später für alle Pachtbetriebe geworden und steht absolut gesichert da. [...] Ich kenne Herrn Klepper seit langen Jahren und weiß, daß er nach jeder Richtung landwirtschaftsfreundlich eingestellt ist, die Notlage der Landwirtschaft genau kennt und seine ganze Kraft für deren Sanierung einsetzen wird." Auch der Aufsichtsrat der Domänenbank protestierte in einem offiziellen Schreiben, dankte Klepper „für die erfolgreiche Leitung der Domänenbank" und „versichert ihn seines uneingeschränkten Vertrauens" $"$ ".

Die liberalen Zeitungen reagierten positiv. Die Vossische Zeitung bezeichnet die Ernennung, die in einer für den Sturz parlamentarischer Regierungen eher als für den Wechsel innerhalb eines Verwaltungsapparates üblichen Form erfolgt $\operatorname{sei}^{12}$, als „einen kühnen und guten Griff, indem [die preußische Regierung] dem schärfsten und scharfsinnigsten Kritiker der Preußenkasse Gelegenheit gibt, es an Ort und Stelle besser zu machen"13. Der Berliner Börsen-Courier, die Frankfurter Zeitung und der Vorwärts lobten Kleppers Leistungen und erhofften eine baldige Besserung der Zustände in der Preußenkasse ${ }^{14}$. Diese wurden allerdings auch von den Rechtsparteien kräftig kritisiert und für änderungsbedürftig gehalten, ja man bescheinigte Klepper sogar die dafür notwendige Kompetenz und lobte seine "ungewöhnliche Aktivität"15.

Das sehr kontroverse Bild, das sich hier, bereits am Anfang seiner Karriere, abzeichnete, zeigt, daß sich an Klepper schon früh die Geister zu scheiden begannen, daß seine Person zu Stellungnahmen herausforderte und daß er sich mit seinen Überzeugungen und den daraus resultierenden Taten ebenso unbedingte Anhänger wie scharfe Gegner

\footnotetext{
9 PrLT, 366. Sitzung, 26. 3. 1928, Sp. 26091 ff. Vgl. auch Wygodzinski/Müller, S. 178: „Eine Stimmung berechtigten Unmuts, gemischt mit übereifriger Kritik, hastendem Reformstreben, ernster Besorgnis über die Lage der Landwirtschaft und politischen Interessen und Bedürfnissen, die beim parlamentarisch-politischen System unvermeidlich sind, führte Ende 1927 zu einer Änderung in der Leitung der Preußenkasse. Unter anderem sollte sie dem Zwecke dienen, die Preußische Zentralgenossenschaftskasse als Instrument einer systematischen, sebr hoch und sebr weit gesteckte Ziele verfolgenden Agrarpolitik zu benutzen." (Hervorhebung im Original)

10 Berliner Tageblatt, 13. 1. 1928, "Reorganisation der Preußenkasse“.

11 GSTAM, VNL-K, Nr. 142, v. Bernuth an v. Wangenheim, 10. 2. 1928, als Kommentar zu einem Artikel der Deutschen Tageszeitung, Nr. 57 von 3. 2. 1928, in dem Klepper u. a. auch für Maßnahmen angegriffen wurde, für deren Veranlassung er gar nicht verantwortlich war. Vgl. ebenda, Nr. 177.

${ }_{12}$ Noch drei Tage nach seiner Ernennung steht im ND-P.Z. zu lesen: „Die Flut der Presseäußerungen zum Wechsel in der Leitung der Preußischen Zentralgenossenschaftskasse ebbt nicht ab“ (Nr. 13, Bl. 3).

13 Vossische Zeitung, 16.1. 1928.

${ }_{14}$ Zitiert in: DGBkA, ND-P.Z., Nr. 11, 13. 1. 1928, Bl. $3 \mathrm{ff}$.

15 Vgl. PrLT, 264. Sitzung, Sp. 23172.
} 
machte. Topf schien wieder recht zu haben mit seiner Kommentierung: „Der Hecht war in den Karpfenteich gesetzt worden! “16

Mitte Februar 1928 gab Klepper eine Pressekonferen $z^{17}$, auf der er sein bereits angelaufenes Reformprogramm erläuterte. Da es einen Zeitzeugen nicht dieser, aber einer der folgenden Pressekonferenzen gibt, lohnt es sich, einen Ausschnitt aus dessen Schilderung einzuflechten, denn sie vermittelt ein sehr lebendiges Bild von Kleppers Öffentlichkeitsarbeit. „Von den zahlreichen Berliner Pressekonferenzen dürften die, die der Präsident der Preußischen Zentralgenossenschaftskasse, Otto Klepper, veranstaltet, wohl zu den interessantesten und wertvollsten gehören. Denn hier kommt die ungewöbnliche Aktivität, die der junge Rechtsanwalt seit Übernahme seines verantwortungsvollen Amtes unter starken Anfeindungen entwickelt hat, am wirksamsten zur Geltung. Meist kündigt er neue Maßnahmen an, mindestens weiß er über die Fortentwicklung seiner schon länger bekannten Pläne oder die Auswirkungen bereits getroffener Maßnahmen recht Bemerkenswertes zu berichten. Kurzum, es ist immer etwas los, und, was dann außerdem jeden Journalisten fesselt, ist der Eindruck von der ausgeprägten Persönlichkeit dieses Mannes, der wirklich Format hat und wohl überhaupt einer der stärksten politischen Köpfe des öffentlichen Lebens der Gegenwart darstellen dürfte. An Körperlänge nur unterdurchschnittlich erinnert seine untersetzte, gedrungene Gestalt mit dem bäuerlich-breiten Schädel und der kleinen Stubsnase an die Energiegeladenheit einer Bulldogge. Aber, so widerspruchsvoll es klingt, der Gesamteindruck des Mannes mit dem markanten Gesicht und dem mokanten Lächeln um die Lippen, mit der Haltung des typischen alten Frontoffiziers, der diskreten Eleganz der Kleidung und dem weltmännischen Auftreten, bleibt der eines vollendeten Grandseigneurs, der etwa gerade eine Botschafterkonferenz leitet [...]. Seine meist kurzen, aber inhaltsschweren, mit nur halblauter, aber deutlicher Stimme vorgetragenen Ausführungen sind in jeder Beziehung Musterleistungen rednerischer Dialektik. Aus seinem reichen Sprachschatz versteht er mit großem Geschick stets die Ausdrücke herauszugreifen, die in ihrer Nuance am besten die beabsichtigte Wirkung erzielen, wobei er rücksichtslos seine Rede mit einer Fülle ungewöhnlicher Fremdwörter spickt. Und, wenn er somit auf volkstümliche Gemeinverständlichkeit verzichtet, so läßt sich doch nicht leugnen, daß seine haarscharfen Bonmots und gutgezielten Seitenhiebe nur selten ihre Wirkung verfehlen, weil sie nicht plötzliche Explosionen, sondern mit Energie restlos gebändigte Entladungen eines recht impulsiven Temperaments sind." 18

Kleppers Reformprogramm konzentrierte sich auf drei Hauptpunkte: 1. die Reorganisation der Preußenkasse, das heißt ihre personelle Erneuerung und finanzielle Sanierung, 2. die Einführung des neuen Agrarkreditsystems und 3. die Rationalisierung des Genossenschaftswesens. Alle drei Programmpunkte standen in einem engen Zusammenhang und bildeten die Grundlage für eine Agrarreform, die Klepper in zahlreichen Artikeln, Vorträgen und Interviews dargelegt hat ${ }^{19}$.

16 Topf, S. 87.

17 GSTAM, VNL-K, Nr. 142: Die Vertreter von über 70 Zeitungen sind alle namentlich aufgeführt. Hinweis findet sich in Bl.f.Gen., 75. Jg., Nr. 7, 17. 2. 1928, S. 126 (DGBkA), wo das neue Programm detailliert vorgestellt wird.

18 Der Journalist, der sich Piggy nennt, schreibt im Deutschenspiegel, ein Blatt, das keineswegs zu den Sympathisanten Kleppers gehörte, 12.4. 1929 in: BAK, NL-Zarnow, Mappe 48, Ordner Klepper, Bl. 69 (Hervorhebung im Original).

19 Kleppers Artikel siehe Anhang: Veröffentlichungen aus der Weimarer Zeit. 
Seine Überlegungen stützten sich vor allem auf die Forschungen von Thünen, Aereboe und Max Sering, aber auch auf eigene Erfahrungen wie auf die Ergebnisse einer von ihm veranlaßten Untersuchung über „Die Lage der landwirtschaftlichen Großbetriebe in den östlichen Landesteilen“20. Klepper kritisierte die deutsche Agrarpolitik, die „der Erhaltung der vorhandenen Struktur der landwirtschaftlichen Produktion " diene ${ }^{21}$, statt sich im Gegenteil auf den in stetem Wandel befindlichen internationalen Agrarmarkt einzustellen. Von den veränderten Eßgewohnheiten über die sich ständig verbessernden Transport-, Lager- und Verarbeitungsmöglichkeiten bis zu der großen Konkurrenz überseeischer Getreideeinfuhren verlange alles nach einer flexiblen, anpassungsfähigen Agrarproduktion, die auf die Bedürfnisse des Marktes abgestimmt sein müsse und nicht versuchen dürfe, die Volksernährung gewaltsam der gegebenen Art der Agrarproduktion anzugleichen. Klepper erläuterte im einzelnen, wie und warum große Teile der östlichen Böden ungeeignet für einen rentablen Anbau seien, und wies nach, daß bäuerliche Betriebe wegen der stärkeren Nachfrage nach Veredlungsprodukten krisenfester arbeiteten und weniger verschuldet seien als der Großgrundbesitz, den er allerdings in seinen lebensfähigen Teilen unbedingt erhalten wissen wollte. So sei „die Agrarreform [eine] Voraussetzung für die Anpassung der landwirtschaftlichen Erzeugung an den Markt, also [...] Ausgangspunkt zur Wiedergewinnung der Rentabilität der Landwirtschaft “22. Die Konsequenz dieser Überlegungen war, daß Agrarkredite künftig nicht mehr an zum Sterben verurteilte Betriebe gegeben werden sollten, sondern daß der Kreditvergabe eine betriebswirtschaftliche Prüfung vorausgehen müsse. So gehörte Klepper mit zu den Pionieren, die versuchten, moderne agrarwissenschaftliche Erkenntnisse in praktische Politik umzusetzen. Daß eine so konsequente Agrarreform starken politischen Zündstoff enthielt, läßt sich denken und erklärt einmal mehr, warum die Preußenkasse mitten in die politischen Auseinandersetzungen hineingeriet ${ }^{23}$.

${ }^{20}$ Denkschrift der P.Z. (GSTAB, Nr. 14076). Dazu ausführlich: Schulze, Braun, S. 195 ff. Ehni, S. 70 und Baier, S. $413 \mathrm{ff}$. Baier erwähnt auch den „Vorbericht des 2. Unterausschusses der Wirtschaftsenquête über die Verschuldungsverhältnisse der deutschen Landwirtschaft vom 1. März 1928, [der] erstmalig eine Analyse der Verschuldungs- und Rentabilitätsverhältnisse der deutschen Landwirtschaft" bot. Vgl. den Kommentar der Pommerschen Tagespost, der die „unerhörte Einseitigkeit" des Berichts kritisierte und vermerkte, daß die „Gründe für die Überschuldung [...] in voller Schwere auf die Regierung selbst zurückfallen“. Die Zeitung zitiert eine Entschließung des Reichs-Landbundes, die „jeden Aufkauf von Land größeren Stils“ ablehnt und statt dessen die "Schaffung eines Besitzerhaltungsfonds“ und „Absatzregulierung durch Zollund Handelspolitik" fordert (DGBkA, ND-P.Z., Nr. 296, 4. Jg., 20. 12. 1928). Vgl. außerdem: Georg Schmidt, der die Denkschrift lobt, die die Verschuldung der landwirtschaftlichen Betriebe im Osten Deutschlands übersichtlich schildere, auf die eigentlichen Krisengebiete hinweise und dadurch einer Verallgemeinerung für ganz Deutschland entgegenwirke (S. 10).

${ }^{21}$ Klepper, Rationelle Agrarpolitik (Ausführliche Darstellung und Kommentierung bei Fiederlein, S. 37 ff.).

22 Ebenda, S. 225. Viele zeitgenössische Autoren, deren Bücher allerdings teilweise erst kurz nach Kleppers Artikel erschienen, bestätigen Kleppers Überlegungen: z. B. Sering, S. 684 f., ebenso heutige Autoren wie z. B.: Muth, Agrarpolitik und Zum Sturz Brünings, Schulz, Baier, Boyens u. a.

${ }^{23}$ Fritz Lübkes, der in der Weimarer Zeit bei der Rentenbankkreditanstalt war, schrieb am 16.6. 1966 an Herbert Lauffer, daß er „erst nach dem Kriege in vollem Umfang“ die „Richtigkeit“ von Kleppers agrarpolitischen Zielen erkannt habe (Priv.-Kopie). 


\section{Die Reorganisation der Preußenkasse}

„Mit dem übernommenen Apparat der Preußenkasse allein waren die inneren und äußeren Reformen nicht durchzuführen. Klepper stand unter denkbar ungünstigen Umständen vor dem Problem, frische, seinen Intentionen entsprechende, seine Ziele und Ideen verstehende Kräfte heranzuziehen, ohne die vorhandene Beamtenschaft entbehren zu können. “24 Bei aller gebotenen Eile bedurfte die personelle Umgestaltung eines großen Fingerspitzengefühls. Offensichtlich ist Klepper zweigleisig vorgegangen. Einerseits hat er junge Leute, teilweise aus der Domänenbank, als Unterdirektoren mit Privatdienstverträgen in die Preußenkasse geholt, andererseits hat er, wie es der Deutschenspiegel bissig beschrieb, „die vom Regime Semper übernommenen Geheimräte im wesentlichen nur noch mit der Klärung formaler Schwierigkeiten durch korrekte Aktenvermerke betraut" ${ }^{\text {" } 5}$ und sie pensioniert, wenn sie die Altersgrenze erreicht hatten. Laut Engelmann wurde es ,jedem Einzelnen freigestellt, den Zeitpunkt seines Ausscheidens [ ...] zu wählen "26, was durch die Geschäftsberichte von 1928 bis 1932 bestätigt wird ${ }^{27}$. Sie wurden nicht durch neue Beamte ersetzt, wodurch, wie der bereits zitierte Deutschenspiegel anmerkte, „eine ganze Anzahl schöner Anstellungsmöglichkeiten für stellungsuchende Parteilinge verloren[ging]", wodurch aber auch dringend benötigtes Geld eingespart wurde.

Wie Kleppers Arbeitsteam im einzelnen aussah, läßt sich aus der Akte Personalbestand vom 17. Juli 1931 ersehen ${ }^{28}$. Bis auf Heinrich Albersmann, der acht Jahre älter war als Klepper, waren alle anderen gleichaltrig oder jünger. Der größere Teil hatte eine akademische Ausbildung: August Hillringhaus, Herbert Lauffer und Johannes Loest mit Doktorgrad, Wilhelm Schaub und Rudolf Siedersleben ohne. Einige hatten allerdings auch eine abgebrochene Schul- beziehungsweise Universitätsbildung wie Konrad Engelmann und Ernst Possel oder waren Autodidakt wie Albersmann. Fast alle waren verheiratet und hatten teilweise mehrere Kinder, Albersmann sogar acht. Sie hatten vorher in den verschiedensten Berufen gearbeitet.

Die Tatsache, daß, bis auf wenige Ausnahmen, alle entweder schon nach dem 20. Juli $1932^{29}$ oder spätestens 1933 entlassen wurden, läßt bei aller politischen Unterschiedlichkeit auf eine gemeinsame Grundeinstellung, jedenfalls auf eine klare Opposition gegen den Nationalsozialismus, schließen. Allerdings kann man die Entlassung von Kleppers Mitarbeitern 1933 auch politisch verharmlosend als eine Art nicht unberechtigter Revision Klepperscher Personalpolitik interpretieren, wie Faust das tut: „Viele von ih-

${ }^{24}$ Engelmann, S. 16.

25 Der Deutschenspiegel, 12.4. 1929, S. 587. Wie ein Brief Kleppers vom 26. 7. 1930 zeigt, hat er auch für die Witwen verstorbener Mitarbeiter gesorgt, es wurde „Gnadengebührnisse“ genannt (GSTAM, Rep. 151 IC, Nr. 1067, Bl. 209 f.).

${ }^{26}$ Engelmann, S. 16.

${ }^{27}$ Geschäftsberichte der Preußischen Zentralgenossenschaftskasse in DGBkA. Außerdem sind die Geschäftsberichte von 1925-1930 in: GSTAM, Rep. 151 IC, Nr. 10366/67.

${ }^{28}$ GSTAB, Rep. 84a, IA², Nr. 4449 a (betrifft Personalien der P.Z.), Bl. 127, Personalbogen, Bl. 129 132. Nr. 11150, Bl. $194 \mathrm{ff}$.

${ }^{29}$ Lauffer und Possel wurden im Rahmen der Beamtenentlassungen nach der Absetzung der preuBischen Regierung durch v. Papen am 20.7.1932 schon am 12.8.1932 aus dem Direktorium der Preußenkasse entlassen („Sitzung des preußischen Staatsministeriums vom 12.8.32“, R 43 I/2288, Bl. 201-204). 
nen [den jungen Mitarbeiter Kleppers] sind dem kaum vier Jahre später erneut einsetzenden Wandlungsprozeß der Anstalt wieder zum Opfer gefallen. " ${ }^{30}$ Die meisten seiner Mitarbeiter haben sich in privaten Berufen über Wasser gehalten oder sind wie Klepper emigriert. Loest ist bei der Preußenkasse geblieben, hat sich aber stets loyal verhalten ${ }^{31}$. Es gibt nur eine Ausnahme, Rudolf Siedersleben, der sich von den Nationalsozialisten hat vereinnahmen und als Generalbevollmächtigten in die Firma Otto Wolff, die im nationalsozialistischen Sinne nicht als verläßlich galt, einsetzen lassen ${ }^{32}$. In dieser Funktion wird er in China noch einmal indirekt Kleppers Wege kreuzen. Faust beurteilt die von Klepper durchgeführte personelle Umstrukturierung der Preußenkasse als „eine Maßnahme ganz ungewöhnlicher Art, in der sich Rigorosität ebenso wie Machtanspruch ausdrückte" ${ }^{33}$.

Engelmann, der Kleppers personalpolitische Maßnahmen aus nächster Nähe miterlebt hat, beschreibt sie dagegen ganz anders. So stark die Gegensätze innerhalb des Mitarbeiterstabes und die von außen kommenden Belastungen auch gewesen sein mögen, die Zusammenarbeit verlief nicht nur „reibungslos“, sondern war von außergewöhnlicher Qualität. Die Hauptursache dafür sehen sowohl Engelmann wie andere Mitglieder der Preußenkasse in Kleppers „Kunst der Menschenkenntnis und der Menschenbehandlung“. Er führte sein Team, „wenn auch äußerlich mit leichter Hand und unter Überlassung weitgehender Freiheiten im Rahmen der einzelnen Ressorts, so straff und vor allen Dingen so sachlich“, daß es ihm möglich war, „Forderungen an seine Mitarbeiter zu stellen, die eine weniger führungsbegabte Persönlichkeit kaum durchgesetzt hätte“. Auch die Tatsache, daß es ihm gelang, Mitglieder des alten Direktoriums für eine „loyale Mitarbeit für eine längere Periode des Übergangs zu gewinnen, war ein besonderer Beweis seiner Toleranz und Geschicklichkeit“. Diese zeigte sich auch darin, „wie er die neuen Mitarbeiter in ihrer schiefen Stellung, in der sie de facto als Ressortchefs verantwortlich, de jure aber ohne entsprechende Vollmacht waren ${ }^{34}$, zu leiten und, wenn nötig, zu stützen wußte“. Einerseits hörte er sich ihre Sorgen an und zeigte Verständnis, andererseits verlangte er von ihnen weiterzuarbeiten, und zwar „loyal und seriös“, ein Ausspruch, der aus der Zeit der Zusammenarbeit mit den Reichsstellen der Osthilfe stammte und zum Leitmotiv der Zusammenarbeit wurde ${ }^{35}$. Klepper besaß aber offensichtlich auch die Fähigkeit, Widerspruch nicht nur zu ertragen, sondern ihn sogar zu wünschen und positiv auf ihn zu reagieren. So berichtet zum Beispiel ein DVP-Abgeordneter, der in den Ausschüssen der Preußenkasse mit Klepper zusammenarbeitete, daß Klepper die Aus-

${ }^{30}$ Faust, Geschichte, S. 568.

${ }^{31}$ Loest an Klepper, 15.4.53: „Da Sie, Herr Minister, es gewesen sind, dem ich [...] die Erfahrung verdanke, was ein von gegenseitigem Vertrauen getragener Arbeitskreis unter entsprechender Führung zu leisten vermag, war Ihr Gruß für mich von besonderer Bedeutung. In stets dankbarer Erinnerung an die Preußenkasse verbleibe ich..." (K/Kor.).

32 WA Köln, noch nicht geordneter Bestand Otto Wolff, K83-28, Bericht Siederslebens vom 30. 8. 1934 über das Bahngeschäft mit China. Dort erwähnt er, daß er noch bei der Preußenkasse angestellt sei, sein Name taucht aber schon 1933 in den Akten auf. Endgültig übergewechselt zu Wolff ist er 1936.

${ }^{33}$ Faust, Geschichte, S. 568.

${ }^{34}$ Alle waren zunächst nur kommissarisch und erst ab 1. 12. 1931, als Klepper schon Finanzminister war, fest angestellt (GSTAB, Rep. 84a, Nr. 11150, Bl. 194 ff.).

${ }^{35}$ Engelmann, S. 16. Vgl. auch den im Zusammenhang mit dem Aufbau seines Arbeitsteams bei der Domänenbank zitierten Topf und das Urteil Lauffers. 
schußmitglieder anfangs „ein wenig als ungezogene und mit den Lebensverhältnissen doch noch recht wenig vertraute Kinder behandelt" habe, aber, so fährt er fort, „da ich unabhängig bin, habe ich mir erlaubt, mich dagegen aufzubäumen“, und danach sei es „besser geworden“ 36 .

Im Nachlaß Kleppers fand sich ein sehr witziger Beweis für das positive Arbeitsklima in Gestalt einer sehr amüsant und frech aufgemachten Zeitung, die die Kollegen Klepper als Weihnachtsgabe überreicht haben. Alle ziehen sich gegenseitig und alles, von der Genossenschaftsvereinigung über die Osthilfe bis zur Reichspolitik, durch den Kakao; so habe sich zum Beispiel Ende 1929 „die Notwendigkeit herausgestellt, eine neue genossenschaftliche Ideologie erfinden“ zu müssen, da „sich der Geist der neuen Sachlichkeit als ungeeignete Grundlage erwiesen " habe ${ }^{37}$. Offenbar war das Zusammengehörigkeitsgefühl aber nicht nur auf die „obere Etage“ beschränkt, wie der folgende Brief eines früheren Mitarbeiters zeigt: „Jene Jahre, in denen Sie der Preußenkasse als Präsident vorstanden, kann ich zu den glücklichsten meines Lebens rechnen, viele [von uns] erinnern sich gern der schönen Jahre bei der P.Z. [...], weil Sie auch für die Kleinen das nötige soziale Verständnis zeigten. Wir gedenken noch immer des schönen Kasinos, das Sie uns herrichten ließen, sowie der großherzigen Unterstützungen, die Sie den in unverschuldete Notlage geratenen Betriebsangehörigen zuteil werden ließen. “38

Auch Klepper selbst hat dieses Zusammengehörigkeitsgefühl empfunden, davon zeugen viele Briefe wie zum Beispiel dieser zwei Jahre vor seinem Tode geschriebene: „Es war ein glücklicheres Zeitalter, als wir uns damals alle in der Preußenkasse zusammenfanden. Sie begreifen sicher, daß ich mit einer gewissen Wehmut daran zurückdenke. “39 Aus der Nachkriegskorrespondenz ergibt sich, daß Klepper mit den meisten Mitarbeitern, besonders mit Lauffer, Albersmann und Engelmann, auch während der Emigrationszeit, aber vor allem nach dem Kriege eine enge Verbindung hielt.

Im Vergleich zur personellen Umstrukturierung erwies sich die finanzielle Sanierung der Preußenkasse als sehr viel schwieriger. Zunächst mußte „das Mißverhältnis zwischen Eigenkapital und Geschäftsumfang" beseitigt werden, indem Preußen seine Stammeinlage von bisher 45 Millionen RM um 130 Millionen auf 175 Millionen RM erhöhte. Der entsprechende Gesetzentwurf wurde im preußischen Landtag beraten und von der DNVP hart attackiert. Mehrere Entschließungsanträge versuchten, die „Allmacht des preußischen Staates“ und die „viel zu großen Machtbefugnisse des Präsidenten“ zu beschneiden, doch die Anträge wurden im preußischen Landtag abgelehnt ${ }^{40}$. Der Finanzminister Höpker-Aschoff berief sich darauf, daß die Umgestaltung der Preußenkasse „ein alter Wunsch der Genossenschaften“ und auch im Staatsrat einstimmig gebilligt worden sei ${ }^{41}$. So konnte das Gesetz über die Neuordnung der Preußischen Zentralge-

${ }^{36}$ Eugen Leidig (DVP), PrLT, 366. Sitzung, 26. 3. 1928, Sp. 26105.

${ }^{37}$ GSTAM, VNL-K, Nr. 174.

${ }^{38}$ Fritz Werzat an Klepper, 8. 3. 1951. Werzat schreibt, daß ihre Gedanken oft zu Klepper gewandert seien und daß er heilfroh gewesen sei, endlich, 1949, in der FAZ zu lesen, daß er noch am Leben sei (K/Kor.).

${ }^{39}$ Klepper an Loest, 7. 5. 1955 (K/Kor.).

40 Änderungsantrag zum Gesetzentwurf, Nr. 9186, der in der 369. Sitzung, 28. 3.1928 beraten wurde. PrLT, Sp. $26282 \mathrm{ff}$.

${ }^{41}$ Ebenda und DGBkA, ND-P.Z., 4. Jg., Nr. 75, 28. 3. 1928, Bl. 4 ff. 
nossenschaftskasse relativ rasch, am 30. April 1928, im wesentlichen unverändert vom preußischen Landtag verabschiedet werden ${ }^{42}$.

Da sich durch das Gesetz das Verhältnis zu den Genossenschaftsanteilen erheblich zugunsten des Staates verschoben hatte, klangen die Reaktionen aus Genossenschaftskreisen verständlicherweise verbittert, zumal die positiven Folgen des Gesetzes noch nicht sichtbar geworden waren. So war zum Beispiel in den Blättern für das Genossenschaftswesen zu lesen: Mit dem Gesetz „trat an die Stelle der Beratung das Diktat, und statt einem Verhandeln von Gleich zu Gleich auf Grund gemeinsamer Kapitalbeteiligung und jahrzehntelanger Verbundenheit in Arbeit, Gesinnung und gemeinsamen Interessen, sollte der Machtwille des Gläubigers gegenüber dem Schuldner, das Stimmenübergewicht des größten Kapitalbeteiligten den Ausschlag geben“. Man sieht nun die Auseinandersetzungen über die Umgestaltung der Preußenkasse „in den Bannkreis des politischen Kampfes gezogen" ${ }^{\text {"33 }}$. Die Deutsche Allgemeine Zeitung beklagte den zu starken staatlichen Einfluß, die mögliche politische Beeinflussung der bäuerlichen Bevölkerung im Sinne eines einseitigen Agrarprogramms und die Abhängigkeit vom jeweiligen Mehrheitswillen. Die konservative Zeitung Der Tag stellte eine Fülle aggressiver Fragen zur Umgestaltung der Preußenkasse und zur Person Kleppers, während die Frankfurter Zeitung die Haltung der preußischen Regierung verteidigte und aus einer Denkschrift der P.Z. von 1911 zitierte, in der zu lesen sei: „Die Preußische Zentralgenossenschaftskasse ist nicht Selbstzweck. Der Staat hat mit ihr nur eine Lücke in der Organisation des Genossenschaftswesens ausgefüllt, eine Lücke, die das Genossenschaftswesen seinerzeit aus eigener Kraft zu schließen nicht vermochte." Sobald das geschehe, sei die P.Z. entbehrlich, genau das gleiche gelte heute. Deshalb forderte die Zeitung alle ländlichen Genossenschaften zur Zusammenarbeit auf, damit ein rascher Gesundungsprozess eingeleitet werden könne ${ }^{44}$.

Die Genossenschaftler erhielten sogar Schützenhilfe von der Wissenschaft, die die „drei fundamentalen genossenschaftlichen Grundsätze, [...] der Selbsthilfe, [...] der genossenschaftlichen Freibeit und Selbständigkeit und [...] der parteipolitischen Neutralität“, gefährdet sah, weil der Einfluß der Genossenschaften durch das Gesetz geschwächt, der des preußischen Staates und der Parteien aber verstärkt worden sei ${ }^{45}$. Klepper, der ebenfalls von Wissenschaftlern unterstützt wurde ${ }^{46}$, hatte die Reaktion der Genossenschaftler nicht nur vorausgesehen, sondern immer wieder versucht, die Hintergründe seiner Reformen deutlich zu machen: „[...] die Preußenkasse sei früher lediglich Geldausgleichsstelle gewesen, heute sei sie aber vorwiegend Verwalterin fremder Gelder. Sie habe daher nicht nur das Recht, sondern sogar die Pflicht, sich wie jeder andere private Geldgeber um die Verwendung der von ihr ausgegebenen Kredite zu küm-

\footnotetext{
${ }^{42}$ GSTAB, Rep. 84a, Bl. 136 und 151. Gesetzentwurf Nr. 9017, Beratung des PrLT, 366. Sitzung ff., 26. -30. 3. 1928. Endgültige Verabschiedung durch den PrLT am 30. 4. 1928, Pr. Gesetzessammlung 1928, Nr. 19, Bl. $138 \mathrm{f}$.

${ }^{43}$ DGBkA, ND-P.Z., Bl.f.Gen., Nr. 14, 6. 4. 1928, Titelscite: „Die Umgestaltung der P.Z.“.

${ }_{44}$ Kommentare zitiert in: Ebenda, 4. Jg., Nr. 75, 28. 3. 1928: Vgl. auch Faust, Zentralbank, S. 42.

45 Wygodzinski/Müller, S. 178 (Hervorhebungen im Original). Zu Wygodzinski vgl. Schumacher, Land, S. 202.

${ }^{46} \mathrm{Vgl}$. Kämpffer, S. 183. Vgl. auch Aereboe und Brandt.
} 
mern. Die Preußenkasse müsse daher Einwirkungsmöglichkeiten auf die Genossenschaften besitzen." 47

Klepper ließ eine kritische Bestandsaufnahme durch Revisoren erstellen, „um bei den genossenschaftlichen Hauptgeschäftsanstalten den ungefähren Umfang der Schäden festzustellen, die zu bereinigen waren", und um zu prüfen, wie die Umgestaltung des banktechnischen Apparates der Preußenkasse „nach Gesichtspunkten moderner Banktechnik" zu geschehen habe ${ }^{48}$. Bei der Revision kam das ans Licht, was ohnehin in Bankkreisen längst bekannnt war, nämlich die hohe Verschuldung der Deutschen Raiffeisenbank. Es war eine schwere Hypothek für den Neubeginn, aber sowohl die Raiffeisenbank wie die mit vergleichsweise geringeren Verlusten von rund 4 Millionen RM belastete Genossenschaftliche Zentralbank des Reichslandbundes $\mathrm{GmbH}^{49}$ mußten liquidiert werden ${ }^{50}$. Klepper übernahm die Verantwortung, obwohl er persönlich nichts damit zu tun hatte und es für ihn und sein Institut bedeutende Risiken barg. Tatsächlich war es die „Raiffeisenaffaire“, die der Preußenkasse Anfragen im Landtag sowie einen ersten parlamentarischen Untersuchungsausschuß bescherte und damit auch Kleppers Name in der Presse mit dem Vorwurf von Korruption und Mißbrauch in Zusammenhang brachte ${ }^{51}$.

Die Raiffeisenbank, die „52 Jahre lang als Geldausgleichsstelle der Raiffeisenorganisation gearbeitet und sich nach der Sanierung auch wieder befriedigend entwickelt hatte, aufzulösen“, „war ein schwerer Entschluß“, schreibt Faust in seiner Geschichte des Genossenschaftswesens, ohne auch nur ein Wort über die Hintergründe und die Fehlleistungen der Verantwortlichen zu verlieren. Weder die Mitverantwortung von Andreas Hermes, die er als Aufsichtsratsmitglied der Bank für die Verwendung des von der Preußenkasse gewährten Überbrückungskredits von 40 Millionen RM hatte, noch die Tatsache, daß diese 40 Millionen RM eben nicht zu einer „befriedigenden“ Entwicklung der Bank geführt hatten, werden von Faust erwähnt ${ }^{52}$. Dagegen kam der Untersuchungsausschuß des preußischen Landtags zu dem Ergebnis, daß die Raiffeisenbank das ihr von der Preußenkasse „entgegengebrachte große Vertrauen in sehr erheblicher Weise miß-

47 Bl.f.Gen., 75. Jg., Nr. 7, 17. 2. 1928, S. 126.

${ }^{48}$ GSTAM, Rep. 151 IC, Nr. 10366/67. Engelmann erwähnt, daß Klepper von der gleichen Revisorengruppe eine Revision der Domänenbank „nach gleichen scharfen Gesichtspunkten“ durchführen ließ. Es hätten sich „zwar auch Schäden [gezeigt], die aber keine Gefährdung des Institutes darstellten und vor allen Dingen weder der Kreditpolitik, noch der Organisation der Bank zuzuschreiben waren" (S. 15).

${ }^{49} \mathrm{Zu}$ den Gründen der Verschuldung vgl. Puhle, Interessenpolitik, S. 306.

${ }^{50}$ Liquidationsvertrag zwischen der Preußenkasse und der Raiffeisenbank in: GSTAM, Rep. 151 IC, Nr. 10366. 56 Mio. RM ohne Liquidationskosten. Sie trat ab 1.4. 1929 in stille Liquidation. Die Filialen der Raiffeisenbank wurden entweder selbständige Bezirkszentralkassen oder vereinigten sich mit solchen des Reichsverbandes. Vgl. Faust, Geschichte, S. 419 f.

${ }^{51}$ GSTAM, Rep. 169 D, Nr. 33, Bd. 2, Bl. 113 ff.: 8. 3.1929 Urantrag der KP-Fraktion zur „Kreditpolitik der Preußenkasse seit 1924". 16. 5. 1929, auch die SPD-Fraktion fordert einen Untersuchungsausschuß zur „Untersuchung der Kreditgewährung der Preußenkasse an die Raiffeisengenossenschaften “. Der Antrag wird beschlossen. Rep. 151 HB, Nr. 42, B1. 2. Drucksache des PrLT Nr. 2207: 11. 4. 1929 Mißtrauensantrag der KPD gegen den PrFM wegen Verlustgeschäft der Raiffeisenbank. Vgl. auch Deutsches landwirtschaftliches Genossenschaftsblatt, 56. Jg., Nr. 2, 30. 1. 1929, S. 34 und Bl.f.Gen., 76. Jg., Nr. 21, 24. 5. 1929 (DGBkA).

${ }^{52}$ Faust, Geschichte, S. 419. 
braucht" hatte ${ }^{53}$. Laut Topf trage Semper „einen großen Teil der Schuld daran, daß bei der Raiffeisenbank, die doch nur von den Preußenkassenkrediten lebte, eine derartige Mißwirtschaft einreißen und durch Jahre hindurch fortbestehen konnte "54.

Klepper, der den Untersuchungsausschuß leicht dazu hätte nutzen können, die Versäumnisse seiner Vorgänger aufzudecken, tat genau das Gegenteil, er sagte, „das Genossenschaftswesen brauche jetzt, nachdem die Voraussetzungen für seine neuen Aufgaben geschaffen sind, vor allen Dingen Ruhe“, um die anstehenden "Schwierigkeiten“ meistern zu können. Klepper hatte eine Vielzahl von Fragen zu beantworten. Hier ist vor allem interessant, daß er sowohl den damaligen Überbrückungskredit wie auch die seinerzeitige „Aufwendung großer öffentlicher Mittel zur Bereinigung der entstandenen Verluste" bejahte, und zwar beide Male mit dem Hinweis, daß „sonst die gesamte Landwirtschaft schwer geschädigt und das landwirtschaftliche Genossenschaftswesen schwer diskreditiert worden wäre“. Damit bewies Klepper nicht nur sein Bemühen um Sachlichkeit, sondern auch seine Loyalität gegenüber dem landwirtschaftlichen Genossenschaftswesen, was ihm häufig abgesprochen wurde ${ }^{55}$.

Auch der Versuch, die eingefrorenen, also die von den Genossenschaften geschuldeten Kredite zu realisieren, „was angesichts der unglaublichen Geschäftslage der Preußenkasse berechtigt " erschien ${ }^{56}$, stieß auf große Schwierigkeiten. Von konservativer Seite wurde dieses Vorhaben „als ausgesprochen politisch unter sachlichem Mantel“ empfunden, denn damit hänge „die Zerschlagung des Großgrundbesitzes zwangsläufig“ zusammen $^{57}$. Klepper versuchte dagegen, deutlich zu machen, daß die landwirtschaftliche Produktion, „wenn sie rentieren solle, auf eine neue, den Bedürfnissen der Konsumenten

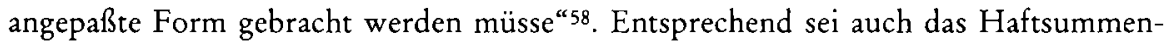
kreditsystem nicht mehr anwendbar, sondern es müsse der Personalkredit, kombiniert mit Rationalitätskontrolle und betriebswirtschaftlicher Beratung, ausgebaut werden.

Obwohl die Genossenschaften prinzipiell das Eingreifen des Staates ablehnten, schien ihnen nun die „Verreichlichung“ der Preußenkasse einen Ausweg aus der zu starken Abhängigkeit vom ,sozialistisch bestimmten' preußischen Staat zu bieten. So setzten sich ihre Vertreter für eine Beteiligung des Reiches an der Finanzierung der Preußenkasse ein, damit die im Reich bereits zunehmend stärker werdenden Rechtsparteien ihren Einfluß für eine konservativere Agrarpolitik geltend machen und gezielter auf die Genossenschaften einwirken konnten. Aber auch Preußen war an einer finanziellen Beteiligung des Reiches gelegen, nur mit einer anderen Begründung: es brauchte Geld, da es selbst nicht in der Lage war, mehr als 75 Millionen RM in den Fonds der Preußenkasse einzuzahlen. So kam es zu Verhandlungen mit dem Reich, die sich allerdings als äußerst

${ }^{53}$ Untersuchungsbericht: „Fall Preußenkasse-Raiffeisen“ des Untersuchungsausschusses im PrLT, der dem Landtag am 9. 5. 1930 in seiner 162. Sitzung vorlag. GSTAM, Rep. 169 D, Nr. 33, Bd. 2 und 3, Bd. 2, Bl. 113 ff., 20. Ausschuß des PrLT, S. 6648 ff., Untersuchungsbericht Nr. 4778 A und B (insgesamt 1966 Druckseiten). Beratung des Berichts: PrLT., Sp. 13830 ff. Vgl. Steffani, S. $210 \mathrm{ff}$.

${ }^{54}$ Topf, S. $655 \mathrm{f}$.

${ }^{55}$ Klepper vor dem Untersuchungsausschuß, DGBkA, ND-P.Z., 5. Jg., Nr. 217, 18. 9. 1929, Bl. 4 ff.

${ }^{56}$ Engelmann, S. 15.

${ }^{57}$ GSTAB, Rep. 87, Nr. 2501, Bl. 8, Bericht von Tietmann, Ministerialrat im RMfLuF, vom 23. 2. 1928.

${ }^{58}$ Bericht von einer Sondertagung der Volkshochschule Rendsburg in: Deutsche Landwirtschaftliche Genossenschaftspresse, 56. Jg., Nr. 21, 15. 11. 1929, S. 480 (DGBkA). 
schwierig erwiesen und sich folglich bis 1930 hinzogen, weil Preußen die Federführung nicht verlieren ${ }^{59}$, das Reich aber stärkere Einwirkung auf die Agrarpolitik in seinem, zunehmend von Großagrariern bestimmten Sinne gewinnen wollte.

Am 23. Januar 1930 konnte das Abkommen zwischen dem preußischen Staat und dem Reich über die Beteiligung des Reiches an der Preußenkasse schließlich doch noch vom preußischen Landtag verabschiedet werden. Das Reich sollte 50 Millionen RM zahlen und dem preußischen Staat einen zinslosen Kredit von 50 Millionen RM gewähren. Damit änderte sich das Verhältnis der Stammeinlagen und entsprechend der Einfluß auf die Besetzung des Direktoriums und der Ausschüsse ${ }^{60}$. Dennoch blieb, zum Leidwesen der Deutschnationalen, der Einfluß des Reiches auf die Geschäftspolitik der PreuBenkasse gering, so wie es der deutschnationale Abgeordnete Georg Gottheiner im Reichstag sarkastisch formulierte: „Für das völlig ungenügende Maß des Einflusses, das dem Reich aus den getroffenen Vereinbarungen erwächst, gibt es wohl keinen besseren Beweis als die Äußerung, die der Präsident der P.Z. selber gestern im Haushaltsausschuß getan hat, in dem er erklärte, daß er die Politik, die er bisher betrieben habe, unbekümmert um andere Meinungen auch in Zukunft fortsetzen werde, das heißt auf deutsch, $\mathrm{da}$ er sich den Teufel darum kümmern werde, was etwa die Reichsregierung einmal sagen werde; es bleibe bei dem, was er für gut befinde." 61

Zwei hauptsächliche Ziele verfolgte Klepper mit seinem Reformprogramm: die finanzielle Unabhängigkeit der Preußenkasse wiederherzustellen und die Selbsthilfekräfte der an die „Treibhausatmosphäre" ständiger „Subventionen und Sonderbegünstigungen verschiedener Art gewöhnte" 62 Landwirtschaft wieder freizulegen und zu mobilisieren.

Diesem Ziel diente auch Anfang Juli 1928 der Erwerb der Aktienmehrheit der „Getreideindustrie- und Commissions AG“, kurz Scheuer-Konzern, nach dem vermittelnden Kaufmann Karl Scheuer, genannt. Dreierlei sollte mit diesem Kauf eines Getreideund Mühlenkonzerns bewirkt werden: Die bis dahin vielfach „eingefrorenen Agrarkredite der Preußenkasse wieder beweglich zu machen “ und „dem Genossenschaftswesen wieder einen größeren Einfluß auf die Entwicklung der Getreidewirtschaft “ einzuräumen. Drittens schließlich „war damals schon damit zu rechnen, daß der Staat sich Einfluß auf die Entwicklung des Getreidepreises verschaffen würde, und bei dieser Aktion wollte sich die Preußenkasse mit dem landwirtschaftlichen Genossenschaftswesen nicht

59 Preußens Argument war, daß es Hauptträger des Grundkapitals sei trotz der 24 der P.Z. angeschlossenen außerpreußischen Verbandskassen. Die Stammeinlagen in Millionen RM verteilten sich folgendermaßen: Preußische Verbandskassen, ländliche: 476,3 und gewerbliche: 32,0; außerpreußische Verbandskassen, ländliche: 64,8 und gewerbliche: 25,7. Die Stammeinlagen der Genossenschaften betrugen nur 35,1, von denen nur 19,1 Millionen RM eingezahlt worden waren (GSTAB, Rep. 84a, Nr. 11150, Bl. 136 und 151).

60 Ebenda, Bl. $187 \mathrm{f}$. und 193, Verordnung zur Änderung der Verordnung über den Ausschuß der P.Z. vom 7. 5. 1924, gez. Braun und Höpker-Aschoff, 6. 2. 1931, betr. Zusammensetzung der P.Z.: bisher: 1 Präsident und 9 Mitglieder (8 Genossenschaftler und 1 Vertreter des FM) und 9 Stellvertreter (1 Vertreter des PrLT und 8 Genossenschaftler), ab 6. 2.1931:17 vom großen Ausschuß zu wählende Mitglieder unter Wegfall der Stellvertreter, 3 von der Reichsregierung benannte Vertreter (je 1 für Finanzen, Ernährung und Landwirtschaft) 2 vom PrStM benannte Vertreter (je 1 für Finanzen und Landwirtschaft), 12 allgemeine, zur Hälfte Genossenschaftler sowie Inhaber von Stammeinlagen und zur Hälfte dem Genossenschaftswesen nahestehende Sachverständige (Pr. Gesetzessammlung).

${ }^{61}$ Zitiert bei Krebs, S. 576.

62 Engelmann, S. 30. 
ausschalten lassen"63. Die vom Untersuchungsausschuß gestellte Frage, warum für die Aktien ein so hoher Preis gezahlt worden sei, beantwortete Klepper lakonisch, „weil die Aktien nicht billiger zu bekommen waren“, und Scheuer verwies zum einen darauf, daß der Erwerb einer Aktienmehrheit immer teuer sei; außerdem hätte das Bankenkonsortium keinen niedrigeren Preis akzeptiert, weil es das Paket nicht unbedingt hätte verkaufen müssen. Es sei ein Angebot für die Genossenschaften auf rein kommerzieller Basis gewesen und habe bereits zu „einem umfangreichen Geschäftsverkehr der Preußenkasse mit den landwirtschaftlichen Genossenschaften " geführt ${ }^{64}$.

Schon im Geschäftsbericht der Preußenkasse für 1928 hieß es: „Die an den gemeinsam mit der Deutschen Rentenbank-Kreditanstalt vorgenommenen Erwerb der Getreideindustrie- und Commissions AG geknüpften Erwartungen haben sich, soweit die Kürze der Zeit eine Beurteilung gestattet, erfüllt. Der in diesen Jahren unternommene Versuch, die Aufgabe der genossenschaftlichen Erntefinanzierung dem Scheuerkonzern zuzuweisen und die Bewegung der Ernte ohne die bürokratischen Formen der bisherigen Erntelombardaktionen in die Bahnen geschäftsmäßig kaufmännischer Umsatztätigkeit zu leiten, hat zu einem guten Anfangserfolg geführt. “ Ein Jahr später hatte sich die Geschäftstätigkeit weiter ausgedehnt, und „die genossenschaftliche Erntefinanzierung [konnte] in verstärktem Umfange durchgeführt" werden ${ }^{65}$. Der Scheuerkonzern hat auch „auf Ersuchen und mit Hilfe der Reichsregierung sehr beträchtliche Getreideeinkäufe teils in Europa, teils in Amerika vorgenommen " und sollte nun auch auf Kleppers Initiative hin bei der Zusammenarbeit mit den Franzosen eingeschaltet werden ${ }^{66}$.

Diesmal kam der Protest weniger von den Landwirten als von den „Handels- und Mühlenvereinigungen, Industrieverbänden und Handelskammern“, man befürchtete eine „Schädigung des freien Handels [...] und verstieg sich schließlich zu der spekulativen Vermutung, die Preußenkasse selbst strebe im Interesse der Genossenschaften ein Getreidemonopol an" ${ }^{67}$. Klepper sah seine Aufgabe lediglich darin, seinen Einfluß darauf zu beschränken, „den Genossenschaften diejenigen Chancen anzubieten, die ihm geboten erschienen, deren Wahrnehmung aber ihrem freien Ermessen überlassen blieb“. Andererseits versuchte er, seinen „vollen Einfluß gegen politische und andere Vorurteile unsachlicher Art, die dagegen vorgebracht wurden“68, einzusetzen. Er konterte: „Es ist nicht wahr, daß die Roggenstützung etwas mit Politik zu tun hat; denn wenn das Politik ist, Roggen teuer einzukaufen, ihn rot anzustreichen und billig zu verkaufen, dann verstehe ich nichts von Politik. "69 In diesem Falle war es die traditionell privatwirtschaftsfeindliche Grundhaltung der Genossenschaften, die einen antisemitischen Hintergrund hatte, denn der Konzern hatte auch nach der Übernahme durch den Staat seine überwie-

${ }^{63}$ Klepper vor dem Untersuchungsausschuß des Reichstages zur Nachprüfung der Roggenstützungsaktion der Reichsregierung, DGBkA, ND-P.Z., 7. Jg., Nr. 35, 11. 2. 1931, Bl. 5. Vgl. Faust, Geschichte, S. 571 und Zentralbank, S. 46.

${ }^{64}$ DGBkA, ND-P.Z., 7. Jg., Nr. 35, 11. 2. 1931, Bl. 5 ff.

${ }^{65}$ DGBkA, Geschäftsbericht der Preußenkasse für 1928, S. 4 und 1929, S. 4.

66 GSTAM, VNL-K, Nr. 157, Bl. 105 f.: Protokoll der 5. Konferenz zwischen den Vertretern der Caisse Nationale de Crédit Agricole (CNCA) und der P.Z. am 19.11. 1931 in Paris. Vgl. auch Protokoll der „Audienz des Herrn Klepper bei Herrn Präsidenten Tardieu, Landwirtschaftsminister, am 31. 10. 1931“, ebenda, Bl. 10 ff., 14 (im übrigen s.u.).

${ }^{67}$ Faust, Geschichte, S. 572.

${ }^{68}$ Engelmann, S. 30.

${ }^{69}$ Dieser Satz wurde als der seine in der erwähnten Festzeitung zitiert, VNL-K, Nr. 174. 
gend jüdische Leitung beibehalten. „Die Art, in der sich Klepper über diese Anfeindungen hinwegsetzte, führte dazu, daß kaum jemand es mehr wagte, sie offen in die Debatte zu werfen. Sie wirkten sich zwar bis zu einem gewissen Grade längere Zeit verborgen aus, traten auch immer einmal wieder in der Presse in Erscheinung, bewiesen aber durch ihre Beschränkung auf Nebenwege des Widerstandes die Autorität und das Zutrauen in die Sachlichkeit seiner Genossenschaftspolitik, die Klepper sich durch die ersten Jahre seiner Amtsführung bei der Mehrzahl seiner maßgebenden Kontrahenten erworben hatte. " 70

\section{Das Institut für landwirtschaftliche Marktforschung}

Auch bei der Preußenkasse wurde nun ein „System landwirtschaftlicher Prüfungs- und Beratungsstellen [errichtet], mit dem Klepper die Methoden einer individuellen, auf fachlichen Grundlagen beruhenden Bemessung des Kreditbedarfes und entsprechender Kontrolle der Kreditverwendung [...] auf die weitere Ebene des gesamten genossenschaftlich organisierten Agrarkredites übertrug "71. Diese Art der Kreditvergabe war neu, ,bisher wurden landwirtschaftliche Kredite nur unter dem Gesichtspunkt der Sicherheit, nicht aber unter dem der rationellen Verwendung ausgegeben "72. Sowohl Landwirte wie Genossenschaften empfanden „diese Betriebskontrolle als Nichtachtung der genossenschaftlichen Prinzipien der Selbsthilfe, Selbstverantwortung und Selbstverwaltung. Versteht man es aber, den Dingen auf den Grund zu gehen, so handelt es sich nur um den Gegensatz zwischen Traditionalismus und Rationalismus." Für fortschrittlich denkende Leute war die Hoffnung, "daß der Gedanke der Rationalisierung (im weitesten Sinne), der von der Preußenkasse bewußt bis zu den entlegensten Einzelgenossenschaften, ja bis zum einzelnen Landwirtschaftsbetrieb getragen wird, schon soviel Früchte gezeitigt hat, daß die traditionalistische Orientierung des landwirtschaftlichen Genossenschaftswesens einer mehr verstandesmäßigen Einstellung " weichen wird ${ }^{73}$, eine Hoffnung, die sich nur sehr langsam erfüllen sollte.

Da Klepper schon in der Zeit als Domänenbankpräsident eng mit der Landwirtschaftlichen Hochschule Berlin zusammengearbeitet hatte, lag es nahe, diese Zusammenarbeit zu institutionalisieren. So gründete Klepper 1929 zusammen mit Karl Brandt, der inzwischen Professor auf dem neu errichteten Lehrstuhl für landwirtschaftliche Marktforschung geworden war, das Institut für landwirtschaftliche Marktforschung, das zwei Beratungsblätter, Bauer und Markt und Blätter für landwirtscbaftliche Marktforschung, herausgab, die sich aus Abonnentengebühren und Inseraten selbst finanzierten. Von der Preußenkasse wurden neun wissenschaftliche und 23 technische Hilfskräfte, die von ihr nach den allgemein geltenden Besoldungsrichtlinien bezahlt wurden, für die Durchführung der Beratertätigkeit zur Verfügung gestellt. Außerdem bezahlte die Preußenkasse

\footnotetext{
${ }^{70}$ Engelmann, S. $30 \mathrm{f}$.

${ }_{71}$ Ebenda, S. 15.

72 Kämpffer, S. 330.

${ }^{73}$ Ebenda, S. 332.
} 
die Kosten des erforderlichen Sachaufwandes von 25000 RM jährlich, Beträge, welche die Hochschule nicht hätte aufbringen können ${ }^{74}$.

Hier ist ein seltener Glücksfall eingetreten und eine enge, sich gegenseitig befruchtende Zusammenarbeit von Wissenschaft und Politik gelungen. Wie eng sie war, zeigt sich unter anderem daran, daß die Wissenschaftler neben ihrer wissenenschaftlichen Forschungstätigkeit für die Preußenkasse arbeiteten ${ }^{75}$ und umgekehrt die Mitarbeiter der Preußenkasse wissenschaftliche Arbeiten veröffentlichten ${ }^{76}$ oder, wie Klepper, publizistisch tätig waren. Doch gerade diese Verbindung von Wissenschaft und praktischer Umsetzung, die obendrein auch noch auf einem von so kontroversen Interessen beherrschten Gebiet wie dem Agrarsektor praktiziert wurde, führte zu unerträglichen Hetzkampagnen, so daß Professor Karl Brandt, der Direktor des Instituts, sich schließlich beim Senat über den Redakteur der Landwirtschaftlichen Wochenschau, Melzer, beschweren mußte, weil dieser „seit dem Tage der Errichtung des Instituts im Jahre 1929 ununterbrochen, meist in wöchentlichem Turnus, und fast stets in verleumderischer Weise gegen mein Institut agitiert“. Dabei wurden Bestechungsvorwürfe, die bis in die Millionen gingen, gemacht ${ }^{77}$. „Bereits 1932 wurde gegen das Institut, seinen leitenden Direktor, Professor Dr. Karl Brandt, und die mit diesem arbeitenden Wissenschaftler von nationalsozialistischer Seite Sturm gelaufen. Sofort nach der Machtübernahme 1933 wurde Professor Brandt seines Amtes enthoben und das Institut durch den neu ernannten preußischen Kultusminister Bernhard Rust aufgelöst. Die Auflösung dieses mit viel Mühe aufgebauten und zur vollen Leistung gebrachten Institutes hatte einen ausgesprochen politischen Charakter."78

Was der Bericht des Untersuchungsausschusses über „die unter Präsident Klepper im Jahre 1928 ins Werk gesetzte Liquidation der Raiffeisenbank“ aussagte, galt für die gesamte finanzielle Sanierung und Umstrukturierung der Preußenkasse, sie war notwendige „Voraussetzung für die Rationalisisierung des Genossenschaftswesens"79. Auch für Klepper selbst war „mit dem Liquidationsbeschluß der Raiffeisenbank [...] die Bahn für den neuen Reichsverband der deutschen Landwirtschaftlichen Genossenschaften-Raiffeisen-E.V. frei geworden" 80 .

\footnotetext{
${ }^{74}$ AdHU, Akte Brandt, Bl. 31 f., 56. Geschäftsbericht von 1929 der P.Z.; auch in den Geschäftsberichten für 1930 und 1931 wird das Institut positiv erwähnt. Hans Wilbrandt, stellvertretender Institutsleiter, bezeichnet in Briefen vom 4. und 14. 4. 1954 an Klepper diesen ausdrücklich als Gründer des Instituts und spricht von dem Klepper-Brandt-Kurs, den auch er vertrat. Wilbrandt wurde zum 30.6. 1933 gekündigt. Klepper bestätigt die Ausführungen Wilbrandts vom 15.4. 1954 offiziell für ein Wiedergutmachungsverfahren (KNL).

75 Vgl. Beckmann u. a. (Hrsg.), Deutsche Agrarpolitik, Bd. II: Brandt, S. 32 ff. und Baade, S. 285 ff. Beide gehen auf die aktuellen Probleme der deutschen Landwirtschaft vor dem Hintergrund der Weltwirtschaft und die Notwendigkeit landwirtschaftlicher Marktforschung ein.

${ }^{76}$ Ebenda Bd. I: Friedrich Ackermann, Direktor bei der P.Z., S. $379 \mathrm{ff}$.

77 AdHU, Akte Brandt, S. 31 ff. Brandt bittet in seinem Bericht an den Senat, „diejenigen Schritte zu ergreifen, die geeignet erscheinen, um der gewissenlosen Hetze entgegenzutreten“. Vgl. Faust, Geschichte, S. 568.

${ }^{78}$ Bericht von Wilbrandt für das Wiedergutmachungsverfahren nach 1945 , Briefe vom 4 . und $14 . /$ 15. 4. 1954, K/Kor.

79 Drucksache des PrLT, Nr. 4778.

${ }^{80}$ Klepper in Exposé I zur Personalfrage des Einheitsverbandes, GSTAM, VNL-K, Nr. 182, Bl. 94 ff. Vgl. auch Exposé II „Die Reorganisation des landwirtschaftlichen Genossenschaftswesens" (Nr. 181, Bl. 37 ff.).
} 


\section{Die Rationalisierung des Genossenschaftswesens}

Die Reform des Genossenschaftswesens durchzusetzen war ein schwieriger Prozeß, der viel Geduld auf beiden Seiten erforderte, wobei das Gegenüber von staatlicher Institution und Genossenschaften keineswegs den Hauptkonfliktstoff barg, viel konfliktreicher waren die Beziehungen innerhalb des Genossenschaftswesens. Dort trafen die unterschiedlichsten Interessen aufeinander: Es gab 36339 landwirtschaftliche Genossenschaften mit rund 4 Millionen Mitgliedern, die vereinigt werden sollten. Faust zählt sie alle auf, von den 20592 Spar- und Darlehenskassenvereinen über 4338 Molkereigenossenschaften bis hin zu 42 Bienenzucht- und Honigverwertungsgenossenschaften. Oft waren in einem kleinen Dorf gleich mehrere Genossenschaften vertreten ${ }^{81}$. Zu der Vereinszersplitterung kamen die unterschiedlichsten traditionellen, politischen, konfessionellen und Standesbindungen, ganz zu schweigen von den regionalen Unterschieden: Konkurrenz zwischen Nord und Süd, zwischen Ost und West, Konkurrenz zwischen Großgrundbesitzern, Kleinbauern und Siedlern und dazu die schon oft zitierte Konkurrenz zwischen dem Reich und Preußen, wie es sich an folgendem Vorgang besonders deutlich zeigt ${ }^{82}$.

Im Frühjahr 1928 beschloß die Reichsregierung ein landwirtschaftliches Notprogramm, zu dem auch 25 Millionen RM zur Sanierung des landwirtschaftlichen Genossenschaftswesens gehörten. Laut Topf „ein gescheit angelegter Gegenzug“ des Reichslandwirtschaftsministers Martin Schiele "gegen das ,sozialistische' Regime Kleppers“. Damit „sollte der neuen Leitung der Preußenkasse ein geschlossenes und nach der Sanierung wieder voll leistungsfähiges Genossenschaftswesen entgegengestellt werden "83. Sollte das tatsächlich Schieles Absicht gewesen sein, so wäre diese Vorgehensweise völlig unrealistisch gewesen, denn erstens mußten die Gelder von irgendeinem Geldinstitut verwaltet und zweitens mußte die Sanierung durchgeführt werden. Keiner der beiden führenden Verbände, weder der Raiffeisen- noch der Reichsverband der deutschen landwirtschaftlichen Genossenschaften (RV), war ohne weiteres geneigt, seine jeweils führende Rolle aufzugeben, von den oben bereits angedeuteten Schwierigkeiten ganz zu schweigen. „Es war bekannt, daß der preußische Staat (überwiegend auf Kleppers Anregung) sich bemühte, diese Mittel durch die Preußenkasse vergeben zu lassen." ${ }^{84}$ Mit der Überweisung der Gelder an die Preußenkasse war Klepper die „Führungsrolle schon deshalb zugefallen, weil letztlich er es war, der über die von den Genossenschaften so dringend benötigten Sanierungsmittel verfügte ${ }^{\text {" } 85}$.

Es wurden „Richtlinien für die Verwendung von Reichsmitteln zur Rationalisierung des landwirtschaftlichen Genossenschaftswesens" mit der Preußenkasse zusammen ausgearbeitet, die genau festlegten, welche Rationalisierungsmaßnahmen finanziell unterstützt und wie sie anteilmäßig verteilt werden sollten. Die Verfügung über die Mittel und deren Anlage bis zu ihrem Einsatz lag beim Direktorium der Preußenkasse; die Bewilligung der Mittel bedurfte der Zustimmung des Reichslandwirtschaftsministers ${ }^{86}$. Klep-

${ }^{81}$ Faust, Geschichte, S. 420.

82 Vgl. Klepper, Exposé I, Bl. 94.

${ }^{83}$ Topf, S. 100.

${ }^{84}$ Engelmann, S. 18.

${ }^{85}$ Faust, Geschichte, S. 418.

86 GSTAM, VNL-K, Nr. 181, Bl. $150 \mathrm{f}$. 
per sah durch den Reichsfonds "nicht mehr als eine Chance gegeben. An den Genossenschaften liegt es, sie zu nutzen." ${ }^{87}$

Im Grunde fiel der Preußenkasse als der Vertreterin des Staates eher eine helfende und vermittelnde Funktion zu, nämlich die Rolle desjenigen, der das mit alten Privilegien und eingefahrenen Vorurteilen durchsetzte, tatsächlich in ein organisatorisches Chaos geratene Genossenschaftswesen zu sanieren hatte, um, ganz im Sinne Miquels, „Hilfe zur Selbsthilfe“ zu ermöglichen und eine effizientere Agrarpolitik in die Wege zu leiten. $\mathrm{Daß}$ die Genossenschaften sich schwertaten und nur ungern von ihren jeweiligen Privilegien etwas abgaben, war für Klepper verständlich und veranlaßte ihn, sich im Juli 1929, als sich bereits eine positive Zusammenarbeit mit den Genossenschaften abzeichnete, in einem Artikel in der Frankfurter Zeitung prinzipiell zu dem Verhältnis zwischen Genossenschaften und Preußenkasse zu äußern: „Die Preußenkasse ist ein Zweckinstitut; sie darf daher ihre Aufgabe als genossenschaftliche Zentralkreditanstalt ohne Rücksicht darauf erfüllen, wer ihr Hauptanteilseigner ist. Es ist selbstverständlich, daß ein finanzieller Sanierungs- und Rationalisierungsprozeß von der Geldgeberseite stark mitbestimmt werden muß; es bestand für die Preußenkasse kein Anlaß, sich dieser Aufgabe deshalb zu entziehen, weil die Genossenschaften nicht im Besitz der Kapitalmehrheit sind. Andererseits ist die Natur des Genossenschaftswesens als eines zur Selbstverwaltung bestimmten Organismus so selbstverständlich, daß es nicht erforderlich erscheint, sie von seiten der Preußenkasse theoretisch zu fundieren. Praktisch aber werden alle Rationalisierungs- und Sanierungsmaßnahmen, die die Preußenkasse in den letzten 11/2 Jahren durchgeführt hat, darauf hinauslaufen, für alle Beteiligten unerfreuliche Abhängigkeiten, die sich aus allseitigen geschäftlichen Fehldispositionen ergeben haben, zu lösen, also den Weg für die Selbstverwaltung, da wo sie verloren war, neu zu eröffnen. "88

Um diese Einstellung schließlich auch unter den Genossenschaftlern zu verbreiten und das Mißtrauen abzubauen, mußte Klepper viele zähe Verhandlungen führen; es forderte einen diplomatischen Balanceakt zwischen „der notwendigen Anwendung von Druckmitteln und der ebenso notwendigen Aufrechterhaltung der Autonomierechte“. Dabei ging Klepper „nicht selten über die Vollmacht hinaus, die sich für ihn aus den Verwendungsrichtlinien für die Gewährung der Zuschüsse ergaben“, womit er seine Bereitschaft zum Risiko bewies. Er übernahm „nicht für die Anstalt allein, sondern in vielen Fällen persönlich durch Aufnahme seiner Entscheidung in die protokollarischen Unterlagen“ die Verantwortung, wozu „ihn sein schneller Blick für das Wesentliche befähigte" 89 .

Die erste offizielle Begegnung mit den Genossenschaftlern fand gleich zu Beginn von Kleppers Amtstätigkeit statt, und zwar als das „Genossenschaftsparlament“ - das ist der Gesamtausschuß der Genossenschaftsverbände, der als beratendes, mit beschränkten Einspruchsrechten ausgestattetes Gremium dem Direktorium der Preußenkasse beigegeben war -, vom Finanzminister zur Vorstellung des neuen Präsidenten einberufen, am 10. Januar 1928 zusammentrat. Engelmann schildert die Zusammenkunft als Augenzeuge: „Klepper, der die Versammlung leitete, erteilte einem Redner nach dem anderen

\footnotetext{
87 Klepper, Exposé II, Bl. 42.

${ }^{88}$ Klepper in: Frankfurter Zeitung, 28.7. 1929. Vgl. auch Kämpffer und Klepper, Exposé III, Bl. $274 \mathrm{ff}$.

${ }^{89}$ Engelmann, S. $24 \mathrm{f}$. und 28.
} 
das Wort, ohne auf ihre zum Teil sehr heftigen Angriffe, auch auf seine Person als für die Leitung der Preußenkasse unqualifiziert, einzugehen. Als schließlich auf seine höfliche Frage nach weiteren Wortmeldungen Schweigen herrschte, gab er zunächst einem Vertreter des Finanzministers, der selbst nicht anwesend war, das Wort und ließ ihn die sachlichen Gründe des Leitungswechsels im Namen des Ministers vortragen, worauf es einige erregte $Z$ wischenrufe, aber sonst keine stärkere Reaktion gab. Erst danach nahm Klepper das Wort und erklärte sein Verständnis dafür, daß die Genossenschaften den Wechsel in der Leitung der Anstalt, der tatsächlich einen starken Wandel in ihrer Geschäftsgebarung bedeuten würde, ,mit einem gewissen Unbehagen“ ansähen. Er glaube aber, daß es alsbald gelingen werde, die Genossenschaften davon zu überzeugen, daß ein Kurswechsel in ihrem eigenen Interesse läge. "90 Klepper skizzierte dann kurz die Lage, ohne auf die vorher geäußerten Klagen und Angriffe einzugehen, wobei „er einen solchen Niveauabstand von den vorangegangenen Rednern erreichte, daß nach Beendigung seiner Ausführungen zuerst Schweigen herrschte, und schließlich nur wenige, gemäßigte Gegenäußerungen laut wurden"91. Offensichtlich war ihm die Wiederherstellung einer sachlichen Basis gelungen.

Engelmanns Darstellung mag idealisierend klingen, wenn man sie mit Topfs bissigen Bemerkungen über Kleppers raffinierten Verhandlungsstil vergleicht. Er nennt Klepper einen „außerordentliche[ $n]$ Debatter und Verhandlungstaktiker, der den starken Gegner mit Liebenswürdigkeit einwickelt, mit großen Gesten blufft, aber mit höhnischer Arroganz, mit oft unbeherrschtem Spott den schwachen Gegner niederboxt. Die Hugenotten-Ahnen, mit deren Erbschaft er gern kokettiert, glaubt man ihm aufs Wort. Nichts ist gradlinig und einfach, immer wird mit ,Dessins', mit ,eleganten Lösungen' gearbeitet. Auf eine unbequeme Fragestellung einzugehen - wie töricht! Nur nicht das beantworten, was der Gegner wissen will! (Diese Taktik ist ungewöhnlich erfolgreich gewesen.) Vor allem gilt es, den ,sozialen Dreh' zu finden, die Geste des wahrhaft modernen Menschen mit sozialem Gewissen - das ist heute der Schlüssel zu vielen Pforten. “92 Engelmann begründet seine Einschätzung, die im übrigen durch die Verhandlungsprotokolle, den Schriftverkehr und die Gesprächsnotizen im Nachlaß Klepper bestätigt wird ${ }^{93}$, indem er sagt, Klepper habe darunter gelitten, „wenn ihm Wesenszüge unterstellt wurden, die ihm von Grund aus fremd waren. Er war liberal und tolerant, wo er auf grundsätzliches Verständnis stieß. Dort aber, wo Unerheblichkeiten oder leere Vorwände gegen ihn und sein Programm vorgebracht wurden, versteifte sich sein Überlegenheitsbewußtsein. " 94

90 Engelmann, S. 17.

${ }^{91}$ Die ländlichen und gewerblichen Genossenschaftsverbände gaben am 20.1. 1928 eine programmatische Erklärung zu den Umgestaltungsplänen der Preußenkasse ab, „in der sie neben der unbedingten Wahrung der politischen Neutralität die Vermeidung jeder nichtwirtschaftlichen und nichtgenossenschaftlichen Einwirkung auf die Kreditpolitik der Preußenkasse " forderten, sowie die Verbreiterung der finanziellen Grundlage der P.Z. „durch Beteiligung von Reich, Ländern und anderen für das Genossenschaftswesen in Betracht kommenden Körperschaften“. Einen Monat später erließ der Deutsche Landwirtschaftsrat eine ähnliche Erklärung, Nottagung des deutschen Landwirtschaftsrats am 23. 2. 1928 (zitiert bei Krebs, S. 573).

92 Topf, S. 90.

${ }_{93}$ GSTAM, VNL-K, Nr. 181 f., 184.

94 Engelmann, S. 5, weist in dem Zusammenhang auch auf die doch recht ungewönliche Karriere Kleppers „außerhalb des üblichen professionellen Weges" und ohne den Anschluß an eine Partei hin. 
Eines wird deutlich: Klepper setzte, wenn er von einer Sache überzeugt war, alle Mittel ein, um das gesteckte Ziel zu erreichen. Wenn sich seine Verhandlungspartner nicht von der Notwendigkeit der Sache überzeugen lassen wollten, versuchte er sie zu überreden oder auch unter Druck zu setzen, aber im Mittelpunkt stand für ihn das Ziel, nicht persönlicher Machtgewinn. Einer seiner Verhandlungspartner, Magnus Freiherr v. Braun, der als Landwirt und Raiffeisenvertreter an den Verhandlungen zur Rationalisierung des Genossenschaftswesens beteiligt war, beschreibt die vorherrschende Verhandlungstaktik so: „Unsere häufigen Aussprachen wurden von der Weisheit des weisesten aller Philosophen geleitet, von Wilhelm Busch: Da lob ich mir die Höflichkeit, das zierliche Betrügen. Du weißt Bescheid, ich weiß Bescheid und allen macht's Vergnügen.“ Braun nennt Klepper in diesem Zusammenhang einen „gelehrige[ $n]$ Schüler Niccolò Machiavellis [...], der nicht über Zwirnsfäden stolperte“95. Faust benutzt nur das Machiavelli-Zitat, um Klepper als den Machtmenschen zu charakterisieren, und trägt damit entscheidend zu dem überlieferten Bild Kleppers bei ${ }^{96}$.

„Das eigentliche Problem der Genossenschaftsrationalisierung“ lag für Klepper in dem „Nebeneinander, Gegeneinander, Ineinander von Reichsverband und Raiffeisenverband“. Alle „Ansätze zur Abgrenzung der Arbeitsgebiete, zur Flurbereinigung, haben sich gegenüber fehlgeleitetem Expansionsdrang und persönlichen Rivalitäten der Genossenschaftsbürokratien nicht fortentwickeln“ können. Der RV sei dezentralisiert, der Raiffeisenverband dagegen zentralisiert aufgebaut, „ein Kompromiß zwischen beiden Formen [sei aber] nicht möglich", es gehe nur das eine oder das andere, wobei "theoretische und praktische Gründe [...] für Dezentralisierung “ sprächen" ${ }^{97}$. Nach der Auflösung der Raiffeisenbank war der Raiffeisenverband grundsätzlich „zur Fusion mit dem Reichsverband bereit" $"$.

Wie aus den verschiedenen Sitzungsprotokollen hervorgeht, hat Klepper mit allen Organisationen einzeln verhandelt und überall auszugleichen versucht. So ließ er sich von Otto Gennes, dem Vorstandsmitglied des RV, überreden, Teilverhandlungen mit dem äußerst schwierigen Reichslandbund (RLB) ${ }^{99}$ zuzulassen, nach dem Motto: der „kleine Teilerfolg sei gut für's Ganze“. Der Reichslandbund war durch seine Vertreter Eberhard Graf w. Kalckreuth und Skriebe an den RV herangetreten, weil er an den Geldern des Reichsfonds beteiligt werden wollte. Der Reichslandbund unterhielt ursprünglich einen eigenen Genossenschaftsverband, eine Zentralkasse und Immobilienbesitz, was inzwischen alles liquidationsreif geworden war. Nun glaubte er wohl, wie Klepper vermutete, "seine Mitglieder auch genossenschaftlich erfassen zu sollen“, um „durch die wirtschaftliche Kraft dieser Unternehmung den wirtschaftspolitischen Einfluß zu stärken und die Finanzierung der politischen Bestrebungen zu erleichtern“. Doch, so meinte Klepper, hätten sich diese Hoffnungen bekanntlich, „vorsichtig ausgedrückt, nicht erfüllt. Die Verquickung von Politik und Geschäft hat zusammen mit dem Mangel an ge-

\footnotetext{
${ }^{95}$ Freiherr v. Braun, S. 188. Er war Vertreter von Hohenegg und Hermes im Einheitsverbands-Präsidium für Raiffeisen. Vgl. Topf, S. 101.

${ }^{96}$ Faust, Geschichte, S. 573.

${ }^{97}$ Klepper, Exposé II, Bl. $38 \mathrm{f}$.

98 VNL-K, Nr. 181, Bl. 144, Niederschrift über die 115. Sitzung des Verwaltungsrats des Reichsverbandes der deutschen landwirtschaftlichen Genossenschaften am 23.11. 1928.

${ }^{99}$ Zur Vorgeschichte des Reichslandbundes, der sich am 1. 1. 1921 aus dem Bund der Landwirte und dem Deutschen Landbund konstituiert hatte, vgl. Puhle, Interessenpolitik, S. 37 ff., 305.
} 
nossenschaftlicher Erfahrung " keine Erfolge bringen können ${ }^{100}$. Klepper zeigte sich zunächst „nicht bereit, für eine solche Teilaktion die Hilfe der P.Z. in Aussicht zu stellen“, und zwar, weil er der Ansicht war, „daß die Vereinheitlichung im landwirtschaftlichen Genossenschaftswesen auf der ganzen Linie gleichmäßig erfolgen müsse“101, aber schließlich hat er sich unter „gewissen Voraussetzungen zu einer wesentlichen Hilfeleistung bereit" erklärt. Im Mai 1928 einigte sich der RV mit ihm auf einen Maßnahmenkatalog für den Anschluß des RLB an die Organisation des RV: „1) Liquidation des Genossenschaftsverbandes des Reichslandbundes e.V. und seiner Teilverbände, 2) Liquidation der genossenschaftlichen Centralkasse des RLB e.g.m.b.h., 3) Liquidation der RLB-Einund -Verkauf-Aktiengesellschaft. " 102

Indem Klepper die teilweise erschütterte Autorität der genossenschaftlichen Hauptverbände wiederherzustellen versuchte, schuf er zwar die Voraussetzungen, daß diese das Einigungswerk bis nach unten fortsetzten konnten, handelte sich aber gleichzeitig den Widerstand regionaler Bauernführer ein, die nicht nur Anspruch auf die Besetzung der Führungspositionen anmeldeten, sondern häufig gegen eine zu straffe Zentralisierung waren, weil sie fürchteten, daß diese zur „,Verpreußung und zur Verblödung führen müsse", wie es der Führer der bayrischen Bauernvereine, Georg Heim, ausdrückte ${ }^{103}$.

Klepper drängte auf eine allgemeine Vereinigung und versuchte, die Frage nach der Präsidentschaft insofern etwas zu versachlichen, als er allgemeine Kriterien für einen solchen Präsidenten aufstellte: Dieser ,sollte zunächst möglichst in der Auseinandersetzung zwischen dem alten RV und Raiffeisen keine Rolle gespielt haben, [...] sollte für beide Gruppen ein Außenseiter sein“ und müsse „mit den Problemen der modernen Agrarpolitik auf möglichst solider Grundlage vertraut sein“, sowie selbstverständlich „abseits jener hemmungslosen Agitation der Verantwortungslosen stehen, die in der deutschen Landwirtschaft soviel Unheil anrichten“, aber dennoch solle er „Fühlung mit der gesamten Öffentlichkeit und jene Repräsentationsfähigkeit haben, ohne die nun einmal die Leitung eines derartigen Genossenschaftsverbandes undenkbar" sei. Zu der in der Öffentlichkeit erhobenen Forderung, der neue Präsident dürfe kein Parteipolitiker sein, meinte Klepper etwas hintergründig, daß wahrscheinlich nur ein kluger und erfahrener Parteipolitiker in der Lage sein werde, die „politische Abstinenz“ zu üben, die meist nur gefordert, aber kaum eingehalten werde ${ }^{104}$.

Nach diesen längeren Ausführungen durfte man neugierig sein, wen er nun vorschlagen würde: Es war Andreas Hermes. Obwohl Klepper offensichtliche Einschränkungen machte und zugab, daß Hermes in seinen früheren Ämtern „nicht immer die Erwartungen erfüllt" habe ${ }^{105}$, setzte Klepper sich für Hermes ein, weil er ihn für einen „energi-

100 Klepper, Exposé II, Bl. $37 \mathrm{f}$.

101 VNL-K, Nr. 181, Bl. 73 f., Vertrauliches Schreiben von Gennes an die Mitglieder des Verwaltungsrates des Reichsverbandes vom 18.5. 1928.

102 Ebenda, Bl. $96 \mathrm{ff}$. und eine genaue Kostenaufstellung.

${ }^{103}$ Faust, Geschichte, S. 418.

104 Klepper, Exposé I, S. 94 ff.

${ }^{105}$ Hermes war Finanzminister in der „Hochinflation“, als Unterhändler mit Polen ein "typischer Vertreter der agrarischen Hochschutzzollpolitik“" „Erst als Mitte 1929 auch die Zentrumsminister im Kabinett auf Stresemanns Vorhaltungen hin nicht länger leugnen konnten, daß die politischen Methoden ihres Parteikollegen Hermes indiskutabel seien, mußte er gehen, nachdem er die Verhandlungen mit Warschau (über ein Liquidationsabkommen) durch anderthalb Jahre 
schen, zielbewußten und eminent fleißigen Mann“ hielt, der zu klug sei, „die Sterne vom Himmel herab fordern“ zu wollen, aber erfahren und gewandt genug, um den „Routiniers der Demagogie, die bisher im Reichslandbund das Wort geführt haben, ein Gegengewicht" bieten zu können ${ }^{106}$. Möglicherweise setzte Klepper sich auch aus taktischen Gründen für ihn ein, weil dieser die nicht im RV organisierte Bauernschaft hinter sich hatte und damit ein gewisses Gegengewicht zum RV bildete. Klepper scheint, nachdem sein erster Vorschlag: der Münchner Landesökonomierat Ludwig Hohenegg, auf wenig Gegenliebe gestoßen war ${ }^{107}$, mit Hermes verhandelt zu haben. Jedenfalls haben beide brieflich Gedanken zur bestmöglichen Sanierung des Genossenschaftswesens und diese betreffende Informationen ausgetauscht ${ }^{108}$.

Am 25. Oktober 1928 hatte das Thema „Rationalisierung der Genossenschaften“ zum ersten Mal auf der Tagesordnung des großen Ausschusses der Preußenkasse gestanden. Damals war das Ergebnis, kurz zusammengefaßt, folgendes: Die Lage der Landwirtschaft sei je nach Gebiet unterschiedlich, vor allem einzelne Gebiete im Osten seien krisenhaft, auch die Genossenschaften seien vor allem in bestimmten Gegenden besonders notleidend, sie zu sanieren, sei mit großem Risiko verbunden, die 25 Millionen RM des Reiches reichten nicht aus, daher müsse neben die Stützung durch die Preußenkasse die Rentenbank-Kreditanstalt treten, und schließlich sei die Einheit der Genossenschaften nur freiwillig sinnvoll ${ }^{109}$.

Im Laufe des Herbstes und Winters hatten Raiffeisenverband und Preußenkasse eine Gesamtverständigung erzielt, so daß für Klepper nun der „Zeitpunkt“ für „Verhandlungen über den Zusammenschluß des gesamten ländlichen Genossenschaftswesens“ gekommen schien. In letzten Gesprächen stellte er dem Reichsverband Ende Januar 1929 zwei Möglichkeiten vor, um „die genossenschaftliche Gesamtvereinigung zu erreichen“: Die eine Möglichkeit sei die Auflösung der vorhandenen Spitzenverbände und die Gründung eines einzigen neuen Spitzenverbandes oder der Zusammenschluß der Spitzenorganisationen zu einem Dachverband, um dann allmählich „aus ihm einen Einheitsverband erwachsen zu lassen“. Der RV erklärte dazu, man habe mit einer so losen Vereinigung wie einem Dachverband schon „bei dem Zusammenschluß mit Raiffeisen in den Jahren 1905-1913 schlechte Erfahrungen gemacht und infolgedessen keine Neigung, dieses Experiment zu wiederholen“. Andererseits könne sich der RV noch zu keiner Stellungnahme entschließen, bevor er nicht selbst mit dem Generalverband der Deutschen Raiffeisengenossenschaften verhandelt habe. Außerdem gäbe es noch das ungelö-

hindurch [...] planmäßig verschleppt hatte. Nicht weniger als dreimal hatte innnerhalb dieses Zeitraums das Auswärtige Amt intervenieren müssen, um in Warschau zu retten, was durch Hermes' Schuld verdorben worden war" (Topf, S. 112, S. 46 ff.). Vgl. dazu Fiederlein, S. 40 f. und Ehni, S. 201: Die "Grüne Front", die im Februar 1929 von Hermes und Anton Fehr (für die Bauernschaft), v. Schiele (für den Landbund) und Ernst Brandes (für den Deutschen Landwirtschaftsrat) gegründet worden war, setzte sich im November 1930 für Unterstützungs- und Zollmaßnahmen für den Osten ein. Puhle bezeichnet die "Grüne Front“ bereits als "das Vorspiel zur freiwilligen Gleichschaltung“ (Interessenpolitik, S. 306). Faust, Geschichte, S. 418.

106 Klepper, Exposé I, Bl. $94 \mathrm{ff}$.

107 Faust, Geschichte, S. 418.

${ }^{108}$ KASt, NL-Hermes, I-090-003, AII(3c): Rationalisierung des landwirtschaftlichen Genossenschaftswesens.

${ }^{109}$ Ebenda. 
ste Problem des Präsidentenpostens, den Klepper keinesfalls dem RV allein überlassen wollte ${ }^{110}$.

Am 9. Februar 1929 erklärte sich der RV trotzdem mit beschleunigten Verhandlungen einverstanden, und obwohl die Situation beim RLB noch unklar war, denn bisher hatte nur von Kalckreuth für seine Person zugesagt, konnten die offiziellen Verhandlungen zwischen der Preußenkasse und den Genossenschaftsverbänden endlich am 22. Februar 1929 beginnen ${ }^{111}$. Schon im Juli desselben Jahres "glaubte Klepper“, wie Topf berichtet, "den Reichsverband hinreichend mürbe gemacht zu haben, [denn] an einem der heißesten Julitage des heißesten Sommers 1929 kam in Frankfurt am Main, unter Assistenz der Adepten aus den genossenschaftlichen ,Splitterverbänden', endlich der Kompromiß über den entscheidenden Punkt, die Postenverteilung im Einheitsverband, zustande“. Es kam zum sogenannten „Frankfurter Frieden“ oder „Frankfurter Genossenschaftspakt“, der die grundsätzliche Entscheidung zur Vereinigung besiegelte ${ }^{112}$.

Zwischen Februar und Juli 1929 hatten allerdings noch einmal harte Kämpfe stattgefunden, wobei die Hauptschwierigkeiten offensichtlich vom RV ausgingen. Dieser hatte wohl nicht nur am meisten um sein Prestige zu fürchten, sondern konnte sich auch schmeicheln, beim Reichsminister für Ernährung und Landwirtschaft ein offenes Ohr zu finden, ging es doch auch hier um die Eindämmung des preußischen Einflusses, der in der Person Kleppers bei den Einheitsverhandlungen besonders spürbar wurde. Die im Lagebericht des RV versteckte Kritik richtete sich gegen einzelne Vorkommnisse in einzelnen Regionen, lief aber im Grunde auf die Klage hinaus, daß Klepper den Reichsverband nicht bevorzugt, sondern so wie alle anderen behandelt hatte. Klepper ging in einer Gegendarstellung vom 25. Mai 1929 auf alle einzelnen Punkte ein, woraus sich ein Bild der Schwierigkeiten bei den Verhandlungen ergibt. Er mahnte zur Eile, ,jeder Aufschub abschlußreifer Verhandlungen würde vermeidbare Verluste für das Genossenschaftswesen bedingen“, und entlarve „die Stockung, die in den Verhandlungen über den Einheitsverband eingetreten“ sei, als Folge von „Prestigefragen, die der Reichsverband aufgeworfen" habe"13.

Wenn auch die erste Einigung vollzogen wurde, bedurfte es noch langwieriger Verhandlungen, bis es nur noch „einen Reichsverband an der Spitze, einen Landes- oder Provinzialverband auf der Landes- oder Provinzebene und nur eine Genossenschaft gleicher Art auf dem Dorf" gab"114 und bis ein Rationalisierungsfonds geschaffen worden

${ }^{110}$ GSTAM, VNL-K, Nr. 182, Bl. 3 ff., Verhandlungen zwischen RV und P.Z. am 25. 1. 1929.

111 Ebenda, Bl. $3 \mathrm{ff}$. und 23: „Verhandlungen über den Zusammenschluß des gesamten ländlichen Genossenschaftswesens", beteiligt waren: Aus Berlin: Reichsverband der Deutschen landwirtschaftlichen Genossenschaften (RV), Generalverband der Deutschen Raiffeisen Genossenschaften, Verband Deutscher Bauernorganisationen, Genossenschaftsverband der Deutschen Bauernschaft, sowie aus Koblenz: der Mittelrheinische Genossenschaftsverein und der Genossenschaftsverband des Reichslandbundes. Am 4. 4. 1929 schlug der RV vor, daß er den ersten Präsidenten stellen wolle, und zwar Freiherrn Klemens v. Loe vor und als 2. Stellvertreter Hohenegg. Er wolle 8 von den 12 Sitzen des Verwaltungsrates besetzen und legte eine Entschließung über die Art der Rationalisierung vor. Klepper äußerte sich nicht zu den Forderungen, versprach, sie nur weiterzugeben an die offizielle Verhandlungsrunde (Bl. $131 \mathrm{ff}$.). Vgl. Faust, Zentralbank, S. 45.

112 Topf, S. 108. Faust, Zentralbank, S. 45 und Geschichte, S. 419 f. Meulenbergh, S. 179.

113 „Überblick über den Stand der Rationalisierung im deutschen landwirtschaftlichen Genossenschaftswesen", als Abschrift in: VNL-K, Nr. 182.

114 Meulenbergh, S. 179. 
war, um die Folgen von zusammengebrochenen Genossenschaften für einzelne Genossenschaftler zu verhindern oder zu mildern ${ }^{115}$. Dafür gewährte die Deutsche Rentenbank-Kreditanstalt den gleichen Betrag wie die von der Reichsregierung für die Rationalisierung des Genossenschaftswesens zur Verfügung gestellten 25 Millionen RM, und schließlich erklärte sich die Preußenkasse bereit, „den Teil der Verluste zu tragen, der das Eigenkapital der zu sanierenden genossenschaftlichen Institute überschritt" 116 .

Der neue, am 13. Februar 1930 in Berlin aus der Taufe gehobene Verband hatte einen etwas umständlichen Namen, worin der Kompromißcharakter der Vereinigung deutlich zum Ausdruck kam, nämlich „Reichsverband der deutschen landwirtschaftlichen Genossenschaften-Raiffeisen e.V.“. Der Verband wurde von zwei gleichberechtigten Präsidenten: Landesökonomierat Ludwig Hohenegg und Reichsminister a.D. Andreas Hermes geführt, die sich in einer Besprechung am 27. Januar 1930 beide rückhaltlos für die Vereinigung, eine enge Zusammenarbeit und die Teilung der Kompetenzen unter sich ausgesprochen hatten ${ }^{117}$.

Faust, der offensichtlich mit zweierlei Maß mißt, ist des Lobes voll: „Hermes, der schon früh die Kunst des Taktierens zu großer Meisterschaft entwickelt hatte, wußte sich seiner äußerst schwierigen Aufgabe mit hohem Geschick zu entledigen und an der Spitze der beiden Organisationen eine fruchtbare agrarpolitische Tätigkeit zu entwikkeln. Dennoch wäre es geradezu falsch, in ihm nur den gewandten, klugberechnenden Taktiker zu sehen. Er war eine durch wissenschaftliche Kenntnisse, hohe fachliche Fähigkeiten, Weltläufigkeit und edle Gesinnung so überragende Gestalt, daß niemand seine Autorität anzutasten wagte. [...] Er hat für die deutschen Bauern viel geleistet, und die Agrargeschichte hat ihn in die Reihe der großen Landwirte aufgenommen. "118 Dagegen kommentierte Topf als Zeitgenosse, der die Hintergründe sehr genau kannte, die Auswahl von Hermes folgendermaßen: „Diesen Mann also hat Klepper in die Leitung des genossenschaftlichen Einheitsverbandes hineingeschoben. Andreas Hermes war nicht feinfühlig genug, nach der einmürigen Ablehnung seiner Kandidatur durch die Vertreter des alten Reichsverbandes, sich als desinteressiert zu erklären; er verließ sich auf Kleppers Hilfe und fand nichts dabei, daß er den widerstrebenden Genossenschaften in aller Form aufoktroyiert wurde." 119 Hermes hat Klepper diesen und den anderen wichtigen

115 NL-Hermes, Prozeßakte. Auch nach der endgültigen Vereinigung der Genossenschaften, am 13. 2. 1930, wurden noch ständig Gelder für die Sanierung der Genossenschaften gebraucht, die Klepper sich in zähen Verhandlungen von allen Seiten zu beschaffen wußte. Vgl. Ministerbesprechung des Reichskabinetts am 2. 5. 1930, in: AdR-Brüning, $1964 \mathrm{ff}$.

116 Faust, Zentralbank, S. 45.

117 GSTAM, VNL-K, Nr. 184, Bl. 136f., die Sitzung fand in der Wohnung von Hermes, im Beisein von Generalanwalt Gennes und Vorstandsdirektor Berg, zwei der zukünftigen Vorstandsmitglieder, statt. Außerdem sollten dem Vorstand des Einheitsverbandes noch Otto Rabe und Freiherr v. Braun angehören. Vgl. auch Faust, Geschichte, S. 420 f.

118 Faust, Geschichte, S. 421 ff., 424.

${ }^{119}$ Topf, S. 113. Topfs Aussagen decken sich mit denen Kleppers: Klepper an Lauffer, 2. 5. 1955: „Lübke weiß ja nicht so viel von den Vorgängen in der Preußenkasse und bei der Genossenschaftsrationalisierung, während Hermes bei Ihnen gewiß unterstellt, daß Sie auch die Dessous kennen, zum Beispiel die entscheidenden Verhandlungen, bei denen die Kandidatur Hermes für den Einheitsverband durchgesetzt wurde, haben Sic ja wohl miterlebt." Klepper an Lübke, 26. 5. 1955 : „Sie kennen Hermes ja mindestens ebenso gut wie ich. Ich glaube, man muß ihn immer 
Dienst, den Klepper ihm in seinem Prozeß leistete, nie gedankt ${ }^{120}$. Doch für Klepper zählte damals nur, daß, wie es in Wilhelm Webers „Chronik der deutschen Agrarpolitik 1914-1932“ zu lesen war, die „jahrzehntelange Zersplitterung im deutschen landwirtschaftlichen Genossenschaftswesen und der Richtungsstreit beseitigt “ seien und der Einheitsverband nun "neue Wege zur Förderung des genossenschaftlichen Absatzes“ gehen könne. ${ }^{121}$

\section{Die Preußenkasse und die Osthilfe}

Durch die Reorganisation des Agrarkreditwesens und durch die Rationalisierung der Genossenschaften hatte Klepper Einfluß auf die Agrarpolitik Preußens und damit auch des Reiches gewonnen. Das vorrangige Gebiet der Agrarpolitik wurde immer mehr der Osten, gemäß dem Vers, den Kleppers Mitarbeiter, die sogenannten „Klepperjünglinge“, für ihn zum Weihnachtsfest 1929 in Anlehnung an den Song Marlene Dietrichs reimten:

„Wir sind von Kopf bis Fuß/auf Osthilfe eingestellt.

Sie kostet sehr viel Geld/und hilft gar nichts.

Anträge umschwirren mich/wie Motten das Licht.

Und wenn es kein Geld gibt,/dafür kann ich nicht."122

Die Osthilfe, die sich aus der Grenzhilfe über die Ostpreußenhilfe entwickelt hatte ${ }^{123}$ und schließlich im Jahre 1931/32 zu einer „Schicksalsfrage der deutschen Republik“ geworden war ${ }^{124}$, findet in der wissenschaftlichen Literatur große Beachtung, zumal das Thema immer wieder im Zusammenhang mit Brünings Sturz und dem Scheitern der Weimarer Republik erörtert wurde ${ }^{125}$. Kleppers Versuch, auf die Gestaltung der Osthilfe Einfluß zu nehmen, wird zwar teilweise in der Literatur erwähnt und bei Hertz-Eichen-

wieder anstoßen. Wenn Sie sich an die Verhandlungen über die Genossenschaftskasse erinnern, er hat auch damals viel versprochen und nichts gehalten." (K/Kor). Auch Faust bestätigt, daß Hermes vor allem vom Reichsverband nicht akzeptiert wurde, S. 418 f. Vgl. Topfs vernichtendes Urteil über Hermes, S. $109 \mathrm{ff}$.

120 Klepper hat unter schwierigsten Umständen und selbst in Existenznot einen Entlastungsbrief für Hermes in dessen Prozeß wegen angeblicher Veruntreuung von Genossenschaftsgeldern geschrieben (NL-Hermes, I-090-004), und zwar, wie R. Hartmann in der Festschrift für Hermes bestätigt: „[...] ohne Verzögerung [und] vollständig. Seine gesamte Erklärung war eine glänzende Bestätigung der von Hermes vor Gericht gemachten Aussage und damit der unwiderlegliche Beweis der völligen Unhaltbarkeit des gegen ihn ergangenen Urteils. Diese Aussage Dr. Kleppers ist in der nach dem Urteil verfaßten und dem Reichsjustizministerium eingereichten Rechtfertigungsschrift wörtlich enthalten" (S. 30 ff., DGBkA). Dagegen hat Hermes nach dem Kriege nichts für Klepper in dessen Pensionsangelegenheit getan.

121 Weber in: Deutsche Agrarpolitik, Bd. 2, S. 114; bei dem Richtungsstreit ging es um Dezentralisation oder Zentralisation.

122 GSTAM, VNL-K, Nr. 174.

${ }^{123}$ Hilfsmaßnahmen für den Osten seit dem Ende des Krieges, vgl. Fiederlein, S. 19 ff. und Heinrich/Otto (Hrsg.), Osthilfegesetzgebung.

${ }^{124}$ Hertz-Eichenrode, S. 337.

${ }^{125}$ Ders., Fiederlein, Boyens und Brüning-Festschrift, darin besonders: Schulz und Muth. Widder gibt einen Überblick über die Osthilfe, incl. Zahlenmaterial, S. 70-83. Er hat mit Klepper korrespondiert und sich seine Darstellung teilweise bestätigen lassen (25.11. 1954 und 23. 3. 1955). Holtferich in: HZ, Bd. 235 (1982), S. 605-631, Walz und Graf Borcke-Stargordt. 
rode sowie Fiederlein ausführlicher erörtert, aber außer in Ansätzen wertet keiner der Autoren Kleppers Politik als eine Alternative, die ein Ansatzpunkt für eine Festigung der Weimarer Demokratie hätte sein können. Einerseits ist es ein müßiges Geschäft zu fragen, was hätte sein können, andererseits weisen zahlreiche Autoren ${ }^{126}$ gerade im $\mathrm{Zu}$ sammenhang mit der Untersuchung der Endphase der Weimarer Republik darauf hin, $\mathrm{da} ß$ der Weg in den Abgrund keineswegs zwangsläufig verlief und daß es viele Ansatzpunkte gegeben habe, die zusammengenommen ein Scheitern der Weimarer Republik hätten verhindern können. Klepper bot einen solchen Ansatzpunkt auf dem Sektor der Agrar- und Finanzpolitik, die er als Teil einer allgemeinen Gesellschaftspolitik verstand. Insofern lassen sich am „Fall“ Klepper exemplarisch die Gründe verdeutlichen, warum solche Ansatzpunkte schließlich ungenutzt blieben und warum die vielfältigen Initiativen zur Verteidigung der Demokratie scheiterten.

Kleppers Ernennung zum Präsidenten der Preußenkasse, hinter der man nicht zu Unrecht ein neues agrarpolitisches Programm vermutete, hatte vor allem im Osten eine Art Panik ausgelöst, die sich unter anderem in dem alsbald ausgestreuten Gerücht manifestierte, „Herr Klepper werde sämtliche jungen Leute des Professors Aereboe auf das Land loslassen, es seien schon 700 engagiert, und es sollten bis 8000 werden" ${ }^{\text {"127. In der }}$ Tat hatte Klepper schon gleich nach seiner Amtsübernahme versucht, die Genossenschaften zur Einrichtung betriebswirtschaftlicher Beratungsstellen zu bewegen, und vor allem hatte er in einer Sitzung im preußischen Landwirtschaftsministerium im Juni 1928 durchgesetzt, daß er einen Kommissar nach Ostpreußen entsenden durfte, um die Interessen der Preußenkasse und „der Genossenschaften bei der Umschuldung wahrzunehmen“. Bürgschaften über $5000 \mathrm{RM}$ durften von den Genossenschaften nur noch mit seiner ausdrücklichen Bewilligung übernommen werden, weil das Kreditrisiko für die Genossenschaften sonst zu groß geworden wäre ${ }^{128}$. Hertz-Eichenrode kommentiert diese Initiative der Preußenkasse folgendermaßen: „Ohne Frage handelte es sich hierbei um einen Schachzug der preußischen Regierung, die sich für die bevorstehende Umschuldungsaktion in Ostpreußen rüsten wollte, denn die in Königsberg etablierte landwirtschaftlich-betriebswirtschaftliche Abteilung der Preußenkasse hat den Klepper zustehenden Sitz im Provinzialkreditausschuß wahrgenommen und ein recht kritisches Auge auf das Verfahren gehabt." Dadurch konnte die Preußenkasse Einblick in die Sanierungsmöglichkeiten der Landwirtschaft gewinnen, und die preußische Regierung erhielt ein neues, möglicherweise wirksames Instrument, um auf die Umschuldungspraxis stärkeren Einfluß zu gewinnen, „nachdem sie bei der Ausarbeitung der Ostpreußenhilfe den Initiativen des Reiches hatte nachgeben müssen" ${ }^{129}$.

126 Vgl. die mehrfach zitierte Literatur, vor allem Ehni, S. $11 \mathrm{ff}$.

127 PrLT, 366. Sitzung, Sp. 26091: Hillger-Spiegelberg (DNVP) am 26. 3. 1928. Dies sind die viel zitierten "Klepperjünglinge“.

${ }^{128}$ GSTAB, Rep. 203, Nr. 176, 1, Sitzung im PrMfLuF vom 25.6. 1928. Hillger-Spiegelberg (DNVP) behauptet in der Landtagsdebatte im März 1928, daß die Genossenschaften in Königsberg von der Preußenkasse dazu gezwungen worden seien, Betriebskontrollen mit der Preußenkasse durchzuführen, während Höpker-Aschoff das bestreitet: PrLT, II, 26. und 28. 3. 1928, Sp. 26099 und 26286.

${ }^{129}$ Hertz-Eichenrode, S. 273. Da Hertz-Eichenrode alles im Detail mit den entsprechenden Quellenangaben dargelegt hat (S. 272 ff.), wird hier nur kurz auf das für das Verständnis des Gesamtzusammenhangs Notwendige eingegangen. 
Das erzeugte natülich Unruhe, weil man die Kontrollen fürchtete. Der Oberpräsident von Ostpreußen, Ernst Siehr ${ }^{130}$, sprach sogar davon, daß „seine Autorität untergraben werde", und warnte Ministerpräsident Braun ausdrücklich vor der "großen Gefahr des alleinigen Einflusses der Preußenkasse, vor allem Kleppers“ "131. Die preußische Regierung geriet von allen Seiten unter Druck, und obwohl Braun Klepper in seiner Absicht, so schnell wie möglich zu handeln, unterstützte, trat er ebenfalls für eine Schonung Ostpreußens ein, wo sich die „Krisenerscheinungen [...] nicht zu stark auswirken dürften “. Außerdem forderte er Mittel vom Reich, da Preußen keine habe ${ }^{132}$. So bediente sich die preußische Regierung des Instrumentes Preußenkasse nur halbherzigi ${ }^{133}$, insofern als sie trotz der sehr harten Kritik Kleppers und seines Teams an der gängigen Umschuldungspraxis ${ }^{134}$ dafür eintrat, "daß die Umschuldungsaktion in dem geplanten Umfang loyal durchgeführt werden müsse "135, obwohl unklar sei, woher das Geld kommen solle, und obwohl eine streng vertrauliche Gegendarstellung der Königsberger Umschuldungsbehörde letztlich zu den gleichen Ergebnissen kam wie die Preußenkasse, die im Gutachten positiv erwähnt und der lediglich vorgeworfen wurde, Einzelfälle „unzulässig" verallgemeinert zu haben ${ }^{136}$.

Daß Ostpreußen geholfen werden mußte, darüber waren sich alle einig. „Ostpreußen steht am Abgrund! ${ }^{* 137}$ war damals der Tenor der Sachverständigenberichte. Doch die Frage, wie die Probleme zu lösen seien, geriet immer stärker in propagandistisches Fahrwasser, um so mehr, als die Frage nach der Beschaffung der finanziellen Mittel immer heikler wurde. In dieser Kampagne geriet die Preußenkasse zwischen die Fronten, einmal, weil sie den Finger auf die Wunden legte, und zum anderen, weil sie als staatliches Kreditinstitut eine gewisse Macht besaß. Symptomatisch für die Stimmung ist der fol-

${ }^{130} \mathrm{Zu}$ Siehr vgl. v. d. Groeben in: Persönlichkeiten, S. $312 \mathrm{ff}$.

${ }^{131}$ GSTAB, Rep. 90, Nr. 1073 und Rep. 203, Nr. 177, 3: Der Oberpräsident von Ostpreußen, Siehr, an Friedrich Wilhelm Frankenbach, 8. 12. 1928, und an Braun, 17. 12. 1928: Siehr lehnte einen Kommissar strikt ab.

132 Ebenda Braun in der Besprechung vom 28. 11. 1928.

133 Hertz-Eichenrode, S. $272 \mathrm{ff}$.

${ }_{134}$ Rep. 90, Nr. 1073 und Rep. 203, Nr. 177, 3, Vermerk Frankenbachs vom 28. 11.1928 und 7. 12. 1928, sowie Ergebnisprotokoll einer Chefbesprechung bei Braun am 12. 11. 1928. Die Umschuldungspraxis sei nicht an betriebswirtschaftlichen Maßstäben orientiert und bevorzuge die Großbetriebe. Ebenda: Bericht der landwirtschaftlich-betriebswirtschaftlichen Abt. der P.Z. (Zweigstelle Königsberg) vom 20.2. 1929: von 103 einschlägigen Umschuldungsfällen könnten nur 22 saniert, 11 müßten abgelehnt werden, 41 seien auch nach der Sanierung stark unrentabel und 29 mit größter Wahrscheinlichkeit. Vgl. die oben zitierte Untersuchung über „Die Lage der landwirtschaftlichen Großbetriebe in den östlichen Landesteilen“. In einer Antwort auf eine „Kleine Anfrage“ Henning Carl v. Winterfelds im PrLT vom 23. 2. 1929 wird eine vertrauliche Behandlung der Ergebnisse der Umfrage ausdrücklich zugesagt, Rep. 203, Nr. 177, 3. Genaue Wiedergabe und kritische Würdigung der Denkschrift bei Fiederlein (S. 12 ff.). Dort wird der außerordentlich hohe Verschuldungsgrad vor allem der ostpreußischen Großbetriebe belegt und bemängelt sowie die Tatsache hervorgehoben, daß weder auf die realen Sanierungsmöglichkeiten, noch auf die Beschränktheit der Mittel Rücksicht genommen werde.

${ }^{135}$ GSTAB, Rep. 203, Nr. 176, 2: Der PrFM in der Chefbesprechung vom 28. 11.1928 „über die Umschuldungsaktion im Rahmen der Ostpreußenhilfe" zur Vorlage der Preußenkasse vom 27. 11. 1928.

${ }^{136}$ Ebenda, Stellungnahme Paul Blunks, Landeshauptmann und Vorsitzender des Kreditausschusses, zum Bericht der Preußenkasse, ebenda, Nr. 177, 1: vorläufiges Gutachten des Enquêteausschusses über die Lage der ostpreußischen Landwirtschaft vom 22.11. 1928.

${ }^{137}$ Ebenda, Nr. 177, 2, Blunk an Ob[er]präsident der Provinz Ostpreußen, 22. 1. 1929. 
gende Zeitungskommentar: „Es ist eine verteufelt ernste Sache, die sich in Ostelbien abspielt, und man möchte doch gern wissen, wer sie zu verantworten hat. In Tat und Wahrheit offenbar niemand anders als Herr Dr. Klepper, der Präsident der Preußischen Zentralgenossenschaftskasse. ${ }^{\text {c138 }}$

Nun begannen auch die Reichsministerien schärfer auf die Umschuldungsverfahren zu achten. Da die Weimarer Koalition im Reich ebenfalls regierte, gab es trotz aller divergierender Interessen zwischen Preußen und Reich eine einheitliche agrarpolitische Zielsetzung, hinter der die Reichs- und die preußische Staatsregierung zusammen mit der Preußenkasse gleichermaßen standen und die sie gewillt waren, gegen die Partikularinteressen der meisten östlichen Großagrarier durchzusetzen. Dies wird deutlich in der Antwort des preußischen Landwirtschaftsministers Steiger, der auf die Frage Hindenburgs, wie es sich mit der "großen Mißstimmung gegen die Preußenkasse“, die in der Provinz herrsche, verhalte, antwortete: „Ich glaube nicht, daß eine solche Mißstimmung in großem Umfange besteht. Man hat der Preußenkasse übelgenommen, daß sie den Vorschlag einer Auffangorganisation und einer Zwischenbewirtschaftung ${ }^{139}$ gemacht hat. Man kann über den Vorschlag verschiedener Meinung sein; aber der Sache nach machen wir in anderer Form durch die hier vorgesehene Regelung dasselbe. Meines Erachtens tut man der Preußenkasse mit den Angriffen in einem Teil der Presse unrecht. " 140

Nach außen stand man zusammen, in den internen Auseinandersetzungen zwischen Preußen und Reich scheint Klepper dagegen eine gewisse Sonderrolle gespielt zu haben, insofern als die preußische Regierung sich gerne seiner Initiative, seiner Energie und seines Durchsetzungsvermögens bediente, um den Einfluß Preußens auf die Agrarpolitik, die das Reich schließlich innerhalb seiner Landesgrenzen auszuüben versuchte, zu stärken $^{141}$. Gleichzeitig aber mußten Klepper und die Preußenkasse auch als Blitzableiter für das immer wache Mißtrauen der Reichsregierung dienen, wie es aus dem Aktenvermerk des Ministerialrats Othmar Feßler über die Verhandlungen im Reichsministerium für Ernährung und Landwirtschaft über das Ostpreußengesetz ${ }^{142}$ am 25 . April 1929 hervorgeht. Dort heißt es: „Das preußische Finanzministerium stellte Anträge, aus denen darauf zu schließen ist, daß die Preußenkasse sehr stark darauf hinarbeitet, ihren Einfluß auf die Durchführung des Ostprogramms zu erhöhen und ihre Stellung als Gläubiger zu verbessern. Auch geht sie anscheinend darauf aus, die Rechte des Reichs- und Staatskommissars zu erweitern. Sie wird dabei vom preußischen Finanzministerium unter-

138 Rep. 90, Nr. 1073, 17. 11. 1928. August Müller, Staatssekretär a. D., schrieb über „Ostelbiens Agrarkrise" im Acht-Uhr-Abendblatt, 10.1. 1929, vgl. Archiv für innere Kolonisation, Bd. XXI, S. 28.

139 Abschrift in GSTAB, Rep. 203, Nr. 177, H. 2, S. 1-15. Klepper hatte diesen Vorschlag bereits in den Bericht der Preußenkasse eingebracht und noch einmal offiziell mit präzisen Angaben an seinen Finanzminister Höpker-Aschoff gerichtet, s.u.: Rep. 87, Nr. 2501, Bl. 18-32. Vgl. dazu Hertz-Eichenrode, S. $316 \mathrm{ff}$.

${ }^{140}$ AdR-Müller II, Bd. I, Nr. 157, Ministerratsbesprechung beim Reichspräsidenten am 20. 3. 1929. Damals gab sich der Reichspräsident noch zufrieden, bedankte sich für „die gründliche und sachliche Arbeit" und empfahl den Herren, „soweit sie es noch nicht getan haben, die Provinz selbst anzusehen". Vgl. Hertz-Eichenrode, S. $281 \mathrm{ff}$.

${ }^{141}$ Vgl. Karikatur zur „Aufnahmeorganisation“, KNL, hier siehe S. 49.

142 In der Chefbesprechung vom 16. 3. 1929, bei der auch Klepper anwesend war, hatten sich Preußen und Reich auf den Entwurf eines Gesetzes für die Ostpreußenhilfe geeinigt (AdR-Müller II, Bd. I, Nr. 153). 
stützt; während das preußische Landwirtschaftsministerium zurückhaltender ist. “ ${ }^{143} \mathrm{Im}$ einzelnen wird die Preußenkasse verdächtigt, selbst als Gläubiger von den Zinserleichterungen profitieren und möglichst hohe Reichsgarantien erhalten zu wollen. Außerdem bestehe sie auf der Überprüfung aller bisher vorgenommener Umschuldungen nach den Gesichtspunkten des neuen Gesetzes, wogegen sich die Reichsressorts mit der Begründung wehrten, daß "Nachprüfungen größeren Umfanges das Vertrauen der ostpreußischen Kreise in die Hilfsmaßnahmen schwer erschüttern würden“. Auch die Tatsache, daß Preußen die Kosten für den Staatskommissar übernehmen wolle, deute auf den Einfluß der Preußenkasse. Tatsächlich hat Klepper, unterstützt vom preußischen Finanzministerium, von Anfang an versucht, sich einen möglichst großen Einfluß auf die Ostpreußenpolitik zu sichern und gleichzeitig die Finanzen der Preußenkasse so weit wie möglich zu schonen. Er wollte eben „kaufmännisch handeln“, in die Marktlage eingreifen, wo es nötig schien, und das ausgeliehene Geld möglichst zurückbekommen ${ }^{144}$; ob er damit auch psychologisch geschickt verfuhr, ist allerdings fraglich.

Trotz der Schwierigkeiten zwischen Preußen und Reich kam es zur Einigung, und das "Gesetz zur wirtschaftlichen Hilfe für Ostpreußen “145 konnte „im wesentlichen unverändert“ am 16. Mai 1930 vom Reichstag verabschiedet werden, sogar mit der Zustimmung der Rechtsparteien ${ }^{146}$. Die Einführung eines auch von Klepper geforderten Staatskommissars mit Vetorecht im Kreditausschuß ${ }^{147}$ war gewissermaßen ein Symbol für die gewollte Zusammenarbeit zwischen Reich und Preußen, zumal man sich auf einen liberalen Mann, den Landrat a. D. und Reichstagsabgeordneten (DDP) Heinrich Rönneburg ${ }^{148}$, einigen und den von Hindenburg gewünschten konservativen ehemaligen Oberpräsidenten, Adolf v. Batocki, verhindern konnte. Klepper schickte seinen besten

${ }^{143}$ Vermerk Ministerialrat Feßlers über die Besprechungen im RMfEuL wegen des Ostpreußengesetzes am 25. 4. 1929 (AdR-Müller II, Bd. I, Nr. 180), auch die folgenden Zitate stammen, soweit nicht anders vermerkt, aus dieser Akte.

${ }^{144}$ GSTAB, Rep. 203, Nr. 177, 2, Vermerk über Referentenbesprechung vom 25.1.1929 im Landwirtschaftsministerium.

${ }^{145}$ RGBI. 1929, I, S. 96: Entwurf vom 27. 4. 1929, Anlage zu den Verhandlungen des Reichstages, IV. Wahlperiode, Bd. 435, Nr. 988, 16. 5. 1929. Am 24. 5. 1929 vom PrStM verabschiedet, nachdem in der Sitzung vom 30.4. 1929 zwei gegensätzliche Entwürfe einer Dienstanweisung zur Durchführung des Reichsgesetzes zur Ostpreußenhilfe vom Finanzministerium und von Klepper beraten worden waren (GSTAB, Rep. 90, Nr.682, Die Lage der Provinz Ostpreußen in wirtschaftlicher und kultureller Hinsicht und die Abschnürung vom Reich und Maßnahmen zu deren Besserung, Bd. I, 1929: 3. 5. 1929 Einigung über Entwürfe, 4. 5. 1929 weitere Beratungen). Das Gesetz wies ein Volumen von 174 Millionen RM aus, von denen 159 Millionen RM das Reich aus eigenem Aufkommen beziehungsweise aus Krediten von dritter Seite, die das Reich und Preußen garantierten, aufbrachte, während die Preußenkasse 15 Millionen zur Verfügung stellte, die aber das Reich durch Abschlagzahlung von preußischen Kriegsverlusten finanzieren mußte (Chefbesprechung vom 16. 3. 1929, Dok. Nr. 153). Vgl. auch Wessling, S. 232 f., Schulz, Stützungsmaßnahmen, Borcke-Stargordt, S. 110 ff. und bei Fiederlein, S. 22 f. Angaben zu Aufgaben und Kosten des Gesetzes.

146 Hertz-Eichenrode, S. 284.

147 GSTAB, Rep. 90, Nr. 1073: Aktenvermerk Frankenbachs zur Besprechung, 28. 11. 1928.

${ }^{148}$ Genaueres zur Person und Auswahl Rönneburgs bei Hertz-Eichenrode, S. 285 ff. Dienstanweisungen für den Staatskommissar finden sich in GSTAB, Rep. 87, Nr. 2105, Bl. 95 ff. (13.4.29); Bl. 106 ff. (1.5.29); Bl. 123 (4.5.29); Bl. 129 ff. (24.5.29): endgültig geregelt im Reichsgesetz vom 18.5.29 (RGBl. 1929, I, S. 97), Bl. 139 ff. 
Mann, Herbert Lauffer, als Assistenten von Rönneburg nach Ostpreußen, und das Landwirtschaftsministerium entsandte Oberregierungsrat Tietmann ${ }^{149}$.

Kleppers Stunde schien gekommen. Was waren seine wesentlichen Forderungen? Entsprechend seinen schon oben erläuterten agrarpolitischen Zielen ${ }^{150}$ sah er in der Beseitigung „der Wirtschaftskrise“ im Osten ein „staatspolitisches Ziel“, das „nicht durch generelle Subvention“, sondern nur durch „individuelle Intervention“ verwirklicht werden könne. Im einzelnen stellte er sich darunter eine „betriebswirtschaftliche und produktionsmäßige Umstellung der landwirtschaftlichen Betriebe“ entsprechend "der Nachfrage nach landwirtschaftlichen Erzeugnissen“ vor. Dies sollte sowohl durch organisatorische Maßnahmen wie durch Einräumung von Vorzugskrediten gefördert werden. „Die finanziell gesunden Betriebe [sollten] grundsätzlich und im Hinblick auf die notwendige Beschränkung des Aufwandes der eigenen Verantwortung “ überlassen werden. Ferner trat Klepper für eine ,innere Umschuldung“151 ein, und zwar nur der „sanierungsfähigen Betriebe“, die anderen müßten, zumindest teilweise, liquidiert und der bäuerlichen Siedlung zugeführt werden. Daß Klepper darin eine Möglichkeit der „Angleichung des sozialen Aufbaus des Ostens" an das übrige Deutschland sah und sich davon eine zunehmende „organische Verbindung beider" 152 erhoffte, wird durch Boyens Urteil bestätigt: es sei „nicht in erster Linie darum [...] [gegangen], den Zusammenbruch des gesamten ,Hypothekar- und Personalkredits' zu verhindern, wie es in der Resolution der Siedlungsdirektoren stand, sondern letztlich um das Schicksal des deutschen Ostens und das ostdeutscher Bodenpolitik“. Klepper habe das „als erster richtig erkannt" ${ }^{153}$. Dagegen kann dem Urteil von Gerhard Schulz, „für die Leitung der Zentralgenossenschaftskasse hing das Schicksal des Großgrundbesitzes ausschließlich von der Nachfrage des Anlage suchenden Kapitals ab"154, nicht zugestimmt werden.

Klepper hatte genaue Vorstellungen davon, wie bankrotte Betriebe in Siedlungsland überführt werden sollten. Er hatte schon Ende 1925, in seiner Domänenbankzeit, eine "gemischt-wirtschaftliche Aufnahmeorganisation“ für zusammenbrechende Domänen vorgeschlagen, ohne allerdings bei dem damaligen preußischen Landwirtschaftsminister Steiger damit durchzukommen ${ }^{155}$. Am 29 . November 1928 schlug Klepper dem preußischen Finanzminister erneut eine Auffangorganisation vor, an der das Reich und Preu-

${ }^{149}$ Beide kamen regelmäßig zur Berichterstattung nach Berlin, z. B. fand am 16.6.1929 eine Ressortbesprechung im PrMfLuF über die Durchführung der Osthilfe statt (Rep. 90, Nr. 1075, Bl. 190 f.).

150 Kleppers Artikel über das „Ostprogramm“ vom 25. 4. 1930 wurde seiner Bedeutung wegen im amtlichen Preußischen Pressedienst vom 25. 4. 1930 vollständig abgedruckt, Rep. 203, Nr. 171. Vgl. Kleppers Veröffentlichungen.

151 „Der Gläubiger wurde, sofern dies möglich war, veraniaßt, seine nun ganz oder teilweise vom Reich garantierten Schulden unter Erleichterung der Rückzahlungs- und Zinsbedingungen stehen zu lassen" (Fiederlein, S. 107).

152 Klepper, Ostprogramm, S. 1007.

${ }^{153}$ Boyens, S. 26.

${ }^{154}$ Schulz, Stützungsmaßnahmen, S. 195.

155 GSTAB, Rep. 87, Nr. 2971: In der Denkschrift des Vorstandes der Domänenpächter vom Dezember 1925 „Die wirtschaftliche Lage der preußischen Domänenbetriebe“ (Bl. 240-299) wird eine "gesamtwirtschaftliche Aufnahmeorganisation" vorgeschlagen, die Klepper später auch vor dem Landtag vertrat (PrLT, 24. Sitzung, 14. 12. 1928, Sp. 1554 ff.). In einem Mahnbrief vom 21.6. 1926 wird beim PrMfLuF um Entscheidung nachgesucht, die negativ ausfällt (Briefentwurf des PrMfLuF, 16. 3. 1926, Bl. 302). 
ßen zu je 42,5\%, Mecklenburg mit 5\% und die Preußenkasse mit 10\% beteiligt sein sollten, wobei ein ungedeckter Fehlbetrag von 70 Millionen bleibe, der „auf Anleihewegen zu beschaffen“ wäre. Dadurch werde „dem Staat Land in dem Umfange zugeführt, der für planmäßige Siedlungstätigkeit auf Jahre hinaus erforderlich" sei. Notfalls sollten die heruntergekommenen und von der Gesellschaft aufgekauften Güter auf ein bis drei Jahre zwischenbewirtschaftet werden ${ }^{156}$. Fiederlein sagt, daß „die Preußenkasse keine Sanierung des Großgrundbesitzes, sondern eine Agrarreform mit Hilfe dieser Auffangorganisation durchführen“ wollte ${ }^{157}$, was insofern korrigiert werden muß, als Klepper, wie oben dargelegt, durchaus bestrebt war, den wirtschaftlich gesunden Großgrundbesitz zu erhalten. Es ging ihm nicht um eine ideologisch motivierte Bodenreform, sondern um eine Agrarreform in gesamtwirtschaftlichem Zusammenhang. In seinem Grundsatzartikel „Rationelle Agrarpolitik“ vom 30. Januar 1930 beschreibt er die „Agrarreform als Voraussetzung der Anpassung der landwirtschaftlichen Erzeugung an den Markt, also [...] als Ausgangspunkt zur Wiedergewinnung der Rentabilität der Landwirtschaft, und zwar gerade auch des noch lebensfähigen Teils der Großbetriebe" 158 . Im Gegensatz zum massenhaft unter Zwang vollzogenen Besitzwechsel in der ersten Hälfte des 19. Jahrhunderts ${ }^{159}$ sollte ein rationell gesteuerter Prozeß der Umgestaltung vollzogen werden. Klepper hielt die bestehende Agrarstruktur für unzweckmäBig und erhoffte sich von der „Besiedlung der aufgekauften Betriebe [...] eine gesunde Mischung der Besitzverhältnisse“, einen „Stillstand“ der „Landflucht“ und schließlich eine „aus nationalpolitischen Gründen notwendige Stärkung des Deutschtums in den Grenzprovinzen“. Er konkretisierte seine Pläne durch genaue Zahlenangaben ${ }^{160}$. Wichtig für ihn war, daß der „Vollzug der Hilfsmaßnahmen“ nicht „ausschließlich den lokalen Selbstverwaltungskörpern“ übertragen werden dürfe, denn „sie sind begreiflicherweise vielfach nicht gewillt, gegenüber dem Interessenten die Härte anzuwenden, die nun einmal unvermeidbar ist" ${ }^{161}$.

So zutreffend Kleppers Vorschläge für eine Modernisierung der Landwirtschaft, den Abbau von Subventionen und die Stützung kleinerer bäuerlicher Betriebe im Prinzip waren, so müssen doch einige Einwände geltend gemacht werden: Erstens war zumindest Ostpreußen, was die ländlichen Besitzverhältnisse anbelangte, ein Sonderfall: Laut Klaus v. d. Groeben, der ab 1930 in der Verwaltung in Ostpreußen tätig und später selbst Landrat war, konnte Ostpreußen nicht als Land des Großgrundbesitzes gelten, vielmehr habe die landwirtschaftliche Nutzfläche bei Betrieben über 200 ha $28,7 \%$ und die unter 20 ha $23 \%$ betragen, so daß man sagen könne, daß die mittelbäuerlichen Betriebe überwogen ${ }^{162}$. Zweitens hat es aufgrund liquidierter Betriebe genug Siedlungsland gegeben, nur das Geld fehlte, um die Besiedlung und die damit notwendig verbundene Verbesserung der Infrastruktur durchzuführen. Drittens schließlich, und das scheint der wichtigste Einwand zu sein, ging es nicht nur um wirtschaftliche, sondern um psychologische,

\footnotetext{
${ }_{156}$ GSTAB, Rep. 203, Nr. 177, 2, S. 14, ebenso in: Rep. 87, Nr. 2501, Bl. 18-32.

157 Fiederlein, S. $74 \mathrm{f}$.

${ }^{158}$ Klepper, Rationelle Agrarpolitik, S. 225.

$159 \mathrm{Vgl}$. Puhle, Interessenpolitik, S. $15 \mathrm{f}$.

160 GSTAB, Rep. 203, Nr. 177: Klepper an den PrFM, 29. 11. 1928.

161 Klepper, Ostprogramm, S. 1009.

162 Klaus v. d. Groeben, Brief an die Verf. vom 8. 7. 1995. Vgl. auch v. d. Groeben, Das Land, S. 214 und Ders., Erinnerungen.
} 
kulturelle und politische Faktoren. Um die berechtigten Wünsche nach Stärkung der im Osten abgelegenen und wie im Falle Ostpreußen gar vom Deutschen Reich getrennten Provinzen zu befriedigen, wäre es besonders wichtig gewesen, die Menschen dort für sich zu gewinnen und nicht die ohnehin bestehende Opposition der auch im bäuerlichen Milieu konservativ orientierten Menschen und damit deren Gefühl der Isolation zu verstärken. Albert Grzesinski hatte das als preußischer Innenminister klar erkannt und deshalb in einer Denkschrift an das preußische Staatsministerium 1927 eine "grundsätzliche Änderung der Ostmarkenpolitik Preußens" gefordert, um die konservativen Stände für die Republik zu gewinnen ${ }^{163}$. Dies lag auch in Kleppers Absicht, aber er hat die Bedeutung der Psychologie unterschätzt, was sich deutlich an den Reaktionen ablesen läßt, die seine konkreten Vorschläge hervorriefen.

„Einen derart konkreten Plan, der den Aspekt der Agrarreform in den Vordergrund rückte, hatte bisher niemand unterbreitet. Deshalb erregte er großes Aufsehen, als er durch eine Indiskretion öffentlich bekannt wurde. Die Landwirtschaft glaubte, den ihr ohnehin suspekten Klepper dabei ertappt zu haben, wie er die Siedlung in eine Guillotine für die Großbetriebe verwandelte, und protestierte lautstark. “ In Ostpreußen vermutete man gar ein abgekartetes Zusammenspiel zwischen preußischer Regierung und Klepper zwecks „kalter Sozialisierung der Landwirtschaft“, und die DNVP fand für diese Gelegenheit ihr „auf Jahre hinaus wirksames Verdammungsurteil über alle Versuche, einen konstruktiven Zusammenhang zwischen Agrarkrise und Agrarreform herzustellen“ 164 , sie fand ihren Schlachtruf: „Das ist doch weiter nichts als Agrarbolschewismus!" 165 Wenn die Land- und Siedlungsgesellschaften auch nicht ganz so agitatorisch reagierten, so hegten sie doch trotz aller Einsicht in die Notwendigkeit einer Agrarreform das gleiche Mißtrauen gegen die rote Regierung in Preußen und die Verbindung dieser Regierung zu Klepper, der auf diese ländlichen Institutionen viel zu rigoros wirkte und dem man eine Achtung vor den gewachsenen Strukturen nicht zutraute. Nur daß diese Strukturen ganz verschwinden würden, wenn man nichts tat, das wollte und konnte wohl auch keiner einsehen.

Doch waren es nicht nur diese konservativen Kräfte, die gegen Klepper standen, es waren auch seine eigenen politischen Mitstreiter, die, beeindruckt von der Stärke der konservativen Opposition, nicht zu viel von ihrer Popularität verlieren wollten, weil sie stets eine Wahlniederlage befürchten mußten. So verschanzte sich Steiger, der Kleppers Vorschlag zwar „eine kühne Idee“ ${ }^{166}$ nannte, hinter finanzielle Bedenken, die auch Höpker-Aschoff teilte ${ }^{167}$. Fand Klepper schon bei seiner eigenen Regierung keine Unterstützung, wobei man nicht vergessen darf, daß er parteilos war und keine politische Hausmacht besaß, so konnte er sie erst recht nicht bei der Reichsregierung finden, die auch unter der großen Koalition ständig vor der Konkurrenz Preußens auf der Hut war und

\footnotetext{
${ }^{163}$ GSTAB, Rep. 90, Nr. 1108.

164 Hertz-Eichenrode, S. 318.

165 PrLT, 366. Sitzung, Sp. 1556, 14. 12. 1928.

166 GSTAB, Rep. 87, Nr. 2501: Klepper an den PrMfLuF, 29. 11. 1928 (Bl. 16) und Stellungnahmen von Steiger am 18. 1. 1929 und 6. 2. 1929 (Bl. 64 ff.), der trotz seiner zunächst positiven Reaktion Bedenken äußerte, und zwar, weil er die Einrichtungen seines eigenen Ministeriums, nämlich die Siedlungsunternehmen, die Staatsdomänenverwaltung und die Staatsforstwirtschaft (Bl. 66), einzusetzen wünschte.

167 Ebenda, vgl. auch Hertz-Eichenrode, S. $320 \mathrm{ff.}$
} 
vor allem immer finanzielle Forderungen von Preußen befürchten mußte, um so mehr, als das Reich immer noch Kriegsentschädigungen an Preußen zu zahlen hatte.

Wie man sieht, saß Klepper mit seiner Politik zwischen sämtlichen Stühlen, obwohl viele diese Politik im nachhinein für vernünttig hielten; so bemerkte Brüning am 17. Mai 1932 zu Vertretern des Großgrundbesitzerverbandes: „Die Lage der Landwirtschaft hätte sich gebessert, wenn vor 3 Jahren etwa $10 \%$ der überschuldeten Betriebe versteigert worden wären. " ${ }^{168}$ Braun hatte sich schon am 14. Dezember 1928 im Preußischen Landtag zu der Notwendigkeit, daß sich auch im Osten „volkwirtschaftliche Gesetze durchsetzen" müßten, geäußert ${ }^{169}$ und im März 1930 seinen Finanzminister bedrängt, „daß die Verhältnisse besonders im Osten sich zu einer dort unmittelbar drohenden Lebensgefahr für Reich und Staat ausgewachsen haben und auch über den Einwand ,es ist kein Geld da' schon hinausgewachsen sind, und daher unter Umständen geradezu außergewöhnliche Mittel zur Beschaffung der erforderlichen Geldsummen erheischen“170. Fiederlein bringt das Problem auf den Punkt, wenn er schreibt: „Kleppers Ausführungen mußten, auch wenn sie sachlich weitgehend richtig waren, auf die in ihrer Existenz gefährdeten Agrarier wie ein rotes Tuch wirken, und dies um so mehr, als auch im Jahre 1929 sich ihre Lage verschlechtert hatte." ${ }^{171}$

Die „Härte“, die Klepper aus seiner Sicht als politischen Willen und Fähigkeit, das als notwendig Erkannte durchzusetzen, bezeichnet hätte, war für seine Kritiker Ehrgeiz, Machtstreben, Rigorosität. Dem von ihm mit ausgesuchten Staatskommissar Heinrich Rönneburg fehlte diese Härte, und so mußte dieser erst recht scheitern, da auch er von den gleichen Schwierigkeiten wie Klepper behindert wurde. Rönneburg hat diese selbst in der Chefbesprechung vom 5. Februar 1930 benannt ${ }^{172}$. Neben „organisatorischen Schwierigkeiten“, unter anderem durch nicht ausreichende Kompetenzen für den Staatskommissar ${ }^{173}$, machte sich der „fortschreitende Verfall der Konjunktur" und entsprechender Geldmangel bemerkbar, der alle Berechnungen immer wieder umstieß. Doch ausschlaggebend war auch für ihn die mangelnde Kooperationsbereitschaft des „agrarisch-konservativen Lagers, das in Rönneburg einen Landfremden und Nichtlandwirt befeindete" 174 .

Die zunehmende Unzufriedenheit dieser Kreise machte sich in einem Brief des Landeshauptmanns Blunk an den Reichskanzler Hermann Müller vom 10. Februar 1930 Luft ${ }^{175}$. Trotz dieser Unzufriedenheit, die einerseits angesichts der teilweise wirklich exi-

${ }^{168}$ BAK, R 43 I/2547, zitiert bei Hertz-Eichenrode, S. 327.

169 PrLT, 24. Sitzung, Sp. 1561.

170 Rep. 90, Nr. 1077, PrMinPr an PrFM, 1. 3. 1930.

171 Fiederlein, S. 38.

172 GSTAB, Rep. 90, Nr. 1076: Auszug aus dem Bericht Rönneburgs vom 27. 11. 1929 (Bl. 320 ff.). Vermerk über Besprechung im RMfLuF am 6. 2. 1930, betrifft Osthilfe (Bericht Rönneburgs), Bl. 504 ff. Ebenda Chefbesprechung im PrStM am 5. 2. 1930 über die Fortführung der Osthilfe, Klepper stellt 5 Millionen RM zur Verfügung, sofern die Rentenbankkreditanstalt auf anderem Gebiet den gleichen Betrag gibt (Bl. $432 \mathrm{ff}$.). Siehe auch Berichte Lauffers vom 30.1. 1930 (Bl. 434 ff.), vom 10.3. 1930 und 13.6.1930 (Nr. 1077). Hertz-Eichenrode erläutert die Schwierigkeiten im einzelnen, S. $289 \mathrm{ff}$. und $299 \mathrm{f}$.

173 Rep. 90, Nr. 1076, PrMP an RK, 28. 2. 1930.

174 Vgl. Abschlußbericht von Rönneburg vom 31. 10. 1930 (Rep. 90, Nr. 1078), Hertz-Eichenrode, S. 300. Zum Scheitern der Ostpreußenhilfe von 1929 vgl. Fiederlein, S. $38 \mathrm{ff}$.

175 Brief des Landeshauptmanns Blunk an den RK Müller vom 10.2. 1930 (AdR-Müller II, Nr. 441). 
stenzgefährdenden Not verständlich war, andererseits aber völlig übersah, welche Opfer Preußen und das Reich brachten, um immer wieder Betriebe zu unterstützen, die eigentlich nicht sanierungsfähig waren ${ }^{176}$, steigerte sich der Widerstand gegen die gesamte Institution „Ostpreußenhilfe“ bis zum Eingreifen des Reichspräsidenten ${ }^{177}$. Eine wirklich durchgreifende Agrarreform durchzuführen, wie Klepper sie vorschwebte und wie auch das Reich sie zunächst versucht hatte, schien unter diesen Umständen fast unmöglich, doch wurde sie vollends unmöglich, als Hindenburg sich seit März 1930 für eine großangelegte Osthilfe einsetzte ${ }^{178}$, die Reichsregierung Müller im gleichen Monat stürzte und das neue Kabinett Brüning „die von Hindenburg gewiesene agrarpolitische Linie zu realisieren begann"179.

Mit dem Regierungsantritt Brünings ${ }^{180}$ begann eine neue Phase der Osthilfe, das Einverständnis zwischen Reich und Preußen war beendet, und die Auseinandersetzung um die Osthilfe geriet zur Auseinandersetzung zwischen Preußen und Reich, zwischen Schieles Agrarkonservatismus ${ }^{181}$ und Preußens „rationeller Agrarpolitik“, die Klepper, von Ministerpräsident Braun „mit allen Vollmachten ausgerüstet“ ${ }^{182}$, vertrat. Das Reich hatte zunächst versucht, Preußen aus den Beratungen über eine neue Osthilfe auszuschalten $^{183}$, mußte diese Strategie aber dann auf Drängen Brauns aufgeben ${ }^{184}$. So wies

${ }^{176}$ Besonders die bereits im Ostpreußengesetz vorgesehene, im Januar 1930 errichtete und mit einem Gesellschaftskapital von $20000 \mathrm{RM}$ ausgestattete Treuhandstelle neigte "oft im Gegensatz zu der ihr vorgeschriebenen wirtschaftlichen Betrachtungsweise dazu, ,die Kredite mit subventionsähnlichem Charakter zu bewilligen“", Bericht Rönneburgs zur "Treuhandstelle für Umschuldungskredite" vom 27. 11. 1929 (Rep. 87, Nr. 2105, Bl. 141 ff.). Näheres zur Arbeit der Treuhandstelle und ihrem Konflikt mit der Landschaft: Hertz-Eichenrode, S. $298 \mathrm{ff}$.

${ }^{177}$ Brief des RP an den RK vom 18. 3. 1930 (R 43/1801; abgedruckt bei Borcke-Stargordt, S. 40 ff.). Vgl. die sogenannte "Osterbotschaft" des RP vom 13.3. 1930 (Text bei Hubatsch, S. 109 f.), dazu ausführlich: Fiederlein, S. $42 \mathrm{ff}$.

178 S.o. Brief des RP vom 18.3. 1930.

${ }_{179}$ Hertz-Eichenrode, S. 299.

${ }^{180}$ Zur Vorgeschichte speziell unter agrarpolitischen Gesichtspunkten und zur Rolle Schieles vgl. Fiederlein, S. 49 ff. Vgl. auch Schulz, Brüning, besonders Kap. I.

${ }^{181}$ Vgl. Fiederlein, der "die Ideologie des Agrarkonservativismus“ genau erörtert und Schieles Agrarprogramm zuordnet, S. $61 \mathrm{ff}$.

182 Pünder, 28. 5. 1930, S. 52. Die Betrauung Kleppers bot sich nicht nur wegen seiner fachlichen Kompetenz an, sondern auch, weil die Preußenkasse ihre 400 Millionen RM Außenstände durch das neue Osthilfeprogramm einzubringen hoffte (Protokoll der Kabinettssitzung vom 6.5. 1930, AdR-Brüning, Nr. 32). Hans Schäffer, 1929-1932 Staatssekretär im RFM, führte, sicher im Auftrag Brünings, ein Sondierungsgespräch mit Klepper über dessen "Gedankengänge“ zum „Ostprogramm“. Klepper sagte bei der Gelegenheit, „wenn er mitarbeiten würde, würde er dies loyal tun und sich auf der Basis des gegenwärtigen Programms auf dessen Ziele einstellen“, wobei er volle „Handlungsfreiheit von der preußischen Regierung " habe, ja sie habe sich „in Fragen des ländlichen Kredits so gut wie immer seinen Ratschlägen angeschlossen“ (IfZ, ED 93, Schäffer, Tagebuch, Bd. 29; Anlage, 9. 5. 1930, S. 70).

${ }^{183}$ PrMfLuF an PrMP, 13. 5. 1930, zitiert bei Schulze, Braun, S. 631, und Schicle in Ministerbesprechung vom 6. 5. 1930 (AdR-Brüning, Nr. 27). Dazu: Aufzeichnungen des Staatssckretärs Otto Meissner über eine Besprechung des RP v. Hindenburg mit Reichsminister Schiele und Vertretern des Deutschen Landvolkes vom 23. 10. 1930, abgedruckt in: Politik und Wirtschaft, 1. Teil, S. 445: Die „Kreditpolitik der Preußenkasse“ wird als „stark politisch beeinflußt" und als "starkes Hemmnis für die Absichten" Schieles bezeichnet.

${ }^{184}$ PrMP an RK, 9. 4. 1930, zitiert ebenda, S. 632. 
Brüning „das Reichsernährungsministerium an, Preußen an den Vorbereitungen der neuen Osthilfe-Maßnahmen zu beteiligen“, zumal Brüning sich „die Gegnerschaft Brauns jetzt nicht leisten konnte, die finanziellen Lasten auf möglichst viele Schultern verteilen wollte und nicht zuletzt für den Fall eines erneuten Scheiterns auf die Mitverantwortung Preußens setzte ${ }^{\text {" } 185}$. Dies war keine gute Ausgangsbasis für eine ersprießliche Zusammenarbeit und ein deutliches Zeichen für Brünings taktische Politik des Lavierens zwischen dem, roten Preußen' und der von Hindenburg gestützten konservativen Rechten, vertreten durch Landwirtschaftsminister Martin Schiele. Gerhard Schulz bezweifelt, ob Brüning sich überhaupt je ein Konzept für „ein großes Ostprogramm im Zusammenhang mit einem Gesamtplan für den Ausbau der Wirtschaft" zurechtgelegt habe. „Greifbare Anzeichen“ gebe es keine, es sehe eher nach „taktischem Geschick“ aus, mit dem er versucht habe, „die notorischen und bürokratisch aufbereiteten Probleme einer Lösung zuzuführen" ${ }^{186}$.

Aus den Aufzeichnungen Pünders vom 28. Mai 1930 geht hervor, wie schwierig eine Einigung „hinsichtlich des sogenannten Ostprogramms, das durch die Regierungserklärung besonders angekündigt war und das den besonderen Wünschen des Herrn Reichspräsidenten entsprach “, zu erzielen war. Neben der Konkurrenz des Reichsfinanz- und des Reichsernährungsministeriums, das jeweils „die Federführung“ für sich beanspruchte, seien auch die Verhandlungen mit Preußen „besonders schwierig“ gewesen, seien aber schließlich doch zu einem guten Ende geführt worden, „und zwar in enger Zusammenarbeit mit dem Präsidenten Klepper von der Preußenkasse“187.

Klepper hatte zunächst in zähen Verhandlungen, in denen er seine „Objektivität und Sachlichkeit" immer wieder gegen Unterstellungen von rechts beweisen mußte ${ }^{188}$, durchzusetzen versucht, daß die Preußenkasse neben der Rentenbankkreditanstalt mit 25\% am Stammkapital der neu zu gründenden „Deutschen Ablösebank“ und der preußische Finanzminister an der Bürgschaftsübernahme für Umschuldungsdarlehen beteiligt wurden ${ }^{189}$. Die von Brüning gewünschte finanzielle Beteiligung Preußens an den Osthilfeaufgaben hatte Klepper dagegen strikt und mit Erfolg abgelehnt, nicht nur weil Preußen kein Geld hatte, sondern sicher auch, weil sein Hauptinteresse der Umschuldungsaktion galt. Zum einen standen noch hohe Forderungen der Preußenkasse aus, und zum anderen wollte die Preußenkasse einen möglichst großen Einfluß auf die praktische Gestaltung der Osthilfe und die Agrarreform im Osten gewinnen. „Der Taktiker Klepper hatte wiederum eine Schlacht gewonnen“, während die Gegnerschaft des Großgrundbesitzes nun auch gegen die Reichsregierung wuchs ${ }^{190}$.

${ }^{185}$ Ebenda, S. 682. Vgl. Kabinettssitzung und Ministerbesprechung vom 15. 5. 1930 (AdR-Brüning, Nr. 34).

186 Vgl. Schulz, Brüning, S. $68 \mathrm{f}$.

${ }^{187}$ Pünder, 28. 5. 1930, S. 52. In der Chefbesprechung vom 14. 5. 1930 hatte Reichsfinanzminister Hermann Dietrich sich bereits als Befürworter Kleppers erwiesen, indem er "grundsätzlich“ für die Beteiligung Preußens und die Mitarbeit der Preußenkasse war, da sie „praktisch" sei, Fiederlein, S. 95.

188 Ebenda.

${ }^{189}$ Ebenda, das Reich übernahm die restlichen 50\%. Vgl. Fiederlein, S. $95 \mathrm{f}$.

${ }^{190}$ Fiederlein, S. 96. Vgl. zu den Verhandlungen den Aktenvermerk des Staatssekretärs Schäffer vom 9. 5. 1930, in dem er einen genauen Bericht über Kleppers Einstellungen und Ziele gibt, abgedruckt in: Politik und Wirtschaft, 1. Teil, S. 155 ff., ebenda: Niederschrift über eine Besprechung Paul Silverbergs mit Wilhelm Bötzkes vom 14. 5. 1930, S. $157 \mathrm{f}$. 
Fiederlein beschreibt die Verhandlungen über den Osthilfegesetzentwurf im Detail ${ }^{191}$, so daß dies hier nicht wiederholt zu werden braucht. Es ging um die geographische Begrenzung des Osthilfegebietes, die Einsetzung eines oder zweier Kommissare zur Überwachung und schließlich um die Rahmenbestimmungen für die Durchführung der Osthilfe, die das Reich am liebsten selbst übernommen hätte. Das heikelste Problem aber war die Frage, nach welchen Kriterien die Mittel verteilt werden sollten. „Die Antwort blieb während der ganzen Dauer der Osthilfeaktion umstritten. Sie war ein Politikum ersten Ranges“, denn dahinter steckte die Frage nach der „Erhaltung des derzeitigen landwirtschaftlichen Besitzstandes“, den die östlichen Landwirte gemäß der ,österlichen' Botschaft des Reichspräsidenten erwarteten ${ }^{192}$. In dieser Frage gingen die Meinungen quer durch das Reichskabinett: Martin Schiele und Gottfried Treviranus, der vorgesehene Ostkommissar, vertraten den Standpunkt der Landwirtschaft ${ }^{193}$, Paul Moldenhauer, Adam Stegerwald und Hermann Dietrich verfochten die Meinung der preußischen Regierung, und Brüning "hielt sich aus taktischen Gründen aus dieser Kontroverse heraus"; einerseits „mußte“ er sich „den Gründen des Reichspräsidenten fügen“, andererseits sah er es „aber nicht als Aufgabe der Reichsregierung an, eine Politik radikaler Besitzerhaltung zu betreiben"194. Noch schärfer vertrat die Ministerialbürokratie des Reiches den preußischen Standpunkt, dem sich auch der Reichsverband der deutschen Industrie anschloß ${ }^{195}$.

Der Osthilfegesetzentwurf, der schließlich Ende Mai 1930 dem Reichsrat und dann dem Reichstag zur Debatte zugeleitet wurde, war nach dem Urteil Fiederleins „ein gediegenes und ausgewogenes System der Umschuldung [...], das alle Teile befriedigen konnte" ${ }^{196}$. Allerdings blieb ein großer Ermessensspielraum für die noch ausstehende praktische Umsetzung offen, zumal einige Bestimmungen einer späteren Durchführungsverordnung überlassen worden waren. Viel hing nun davon ab, wer seine personellen Forderungen durchzusetzen vermochte. Demnach hatte die preußische Regierung zunächst nur einen Teilsieg errungen. Das Gefecht ging weiter. Nachdem der Reichstag nach heftigen Debatten die Osthilfevorlage in zweiter Lesung am 17. Juli 1930 angenommen hatte, konnte die Inkraftsetzung des Gesetzes nicht mehr auf parlamentarischem Wege, sondern mußte auf dem Verordnungswege ${ }^{197}$ durchgeführt werden, da der Reichstag inzwischen aufgelöst worden war ${ }^{198}$.

${ }^{191}$ Fiederlein, S. 97 ff. Vgl. Schulz, Brüning, S. 62 ff., besonders S. 72 f.

${ }^{192}$ Fiederlein, S. 104.

193 Ebenda, S. 106.

194 Ebenda, S. 106.

195 BAK, NL-Pünder, Nr. 110, Ludwig Kastl, Geschäftsführer des Reichsverbandes der deutschen Industrie, an RK Brüning, 15. 5. 1930.

196 Fiederlein, S. 108.

197 Verordnung des Reichspräsidenten „zur Behebung finanzieller, wirtschaftlicher und sozialer Notstände“ vom 26. 7. 1930 (RGBl. 1930, I, S. 311 ff.; Auszug, 3. Abschnitt "Osthilfe", abgedruckt bei Borcke-Stargordt, S. 112 ff.). Vgl. Fiederlein, S. 112.

$198 \mathrm{Vgl}$. Bracher, Auflösung, S. $335 \mathrm{ff}$. und Fiederlein, S. $112 \mathrm{f}$. 
Bis es zu den Durchführungsbestimmungen auf dem Notverordnungswege kam ${ }^{199}$, mußte Preußen zäh verhandeln, wobei Braun eher die Fäden im Hintergrund zog und mit dem Reichskanzler sprach, während Klepper die offiziellen Verhandlungen führte. Ziel beider war, die personelle Besetzung der Landstellen in ihrem Sinne durchzusetzen und diese damit zu Instrumenten der preußischen Agrarpolitik zu formen. In den entscheidenden Verhandlungen vom 7. und 8. August setzte Klepper durch, daß es zwei gleichberechtigte Kommissare als Leiter der Oststellen geben sollte und daß diese die Richtlinien für die Verfahren bei der Umschuldung, der betriebswirtschaftlichen Prüfung sowie bei der Verteilung der Mittel erlassen und die Dienstanweisungen für die Landstellen geben sollten. Die preußische Regierung ernannte den Volkswohlfahrtsminister Heinrich Hirtsiefer, die Reichsregierung den Vertrauensmann Hindenburgs und Freund Brünings, Gottfried Treviranus $^{200}$. Bei der Besetzung der Landstellen mußte Klepper zwei Einschränkungen hinnehmen, „die pommersche und die niederschlesische Landstelle wurden von Vertrauensmännern der Reichsregierung besetzt - beides Mitglieder des Reichslandbundes, einer von ihnen der pommersche Osthilfekommissar Johann Georg v. Dewitz, als alter und prominenter Gegner der preußischen Regierung ausgewiesen" ${ }^{201}$. Doch glich Klepper das insofern wieder aus, als v. Dewitz ein leitender Angestellter der Preußenkasse, Direktor Hans Walter Schmidt, als Stellvertreter beigegeben werden konnte ${ }^{202}$. Auch die Leiter der landwirtschaftlich-betriebswirtschaftlichen Abteilungen waren vorwiegend Diplomlandwirte, „die im Geiste Aereboes ausgebildet und oft auch durch die Schule Kleppers hindurch gegangen waren. Dies galt in noch verstärktem Umfange für das ,Bodenpersonal ${ }^{c}$ dieser Abteilungen, die Prüfer und Sachbearbeiter. Ihnen fiel die Prüfung der eingereichten Umschuldungsanträge, der Betriebe und ihrer Leiter zu. Das Schicksal des östlichen Großgrundbesitzes lag nun weitgehend in ihrer Hand."

"Dank ihrer konsequenten [...] und systematischen Verhandlungstaktik", die von „festumrissenen Prämissen“ ausging und „klare Ziele“ verfolgte, hatten sich „Braun und Klepper fast völlig“ gegen „die Wünsche des östlichen Großgrundbesitzes“ durchgesetzt, obwohl diese „im Verlaufe der ganzen Vorbereitungszeit ständig formuliert und an die Reichsregierung herangetragen worden waren“. Als Grund nennt Fiederlein die Tatsache, daß „Schiele sich innerhalb des Kabinetts nicht durchzusetzen vermocht hatte und zudem noch von Klepper laufend überspielt worden war. In organisatorischer wie in personeller Hinsicht hatte das Reich, wenn man es, wie von den Initiatoren des Kabinetts Brüning geplant, als Verteidiger der Belange der östlichen Landwirtschaft ansieht, den kürzeren gezogen. "203 In diesem Erfolg der preußischen Regierung, der unbestritten auch ein persönlicher Erfolg Kleppers war, war allerdings schon der Kern zum Konflikt

${ }^{199}$ Durchführungsverordnung vom 8. 8. 1930 zur Einrichtung von sogenannten Landstellen in Königsberg, Köslin, Schneidemühl, Breslau und Oppeln und Durchführungsverordnung vom 3. 9. 1930 zur Aufnahme der Geschäftstätigkeit der Landstellen ab 10. 11. 1930, Umschreibung ihres Aufgabenbereiches und Bestimmung der Zusammensetzung der Beiräte (Fiederlein, S. 120).

200 Vgl. Ministerbesprechung vom 7. 8. 1930 und 8. 8. 1930 (AdR-Brüning, Nr. 96).

201 Schulze, Braun, S. 682 f.: v. Dewitz hat sich dann auch als Quertreiber erwiesen und sich unter Umgehung der Reichskommissare direkt an Hindenburg gewandt und sich bitter beschwert. Zur Affäre v. Dewitz vgl. auch Fiederlein, S. 182-192, der der Affäre zehn Seiten widmet und meint, man müsse den Fall aufgrund des Aktenmaterials differenzierter betrachten.

202 Brief Schmidt an Lauffer, 15. 5. 1931 (VNL-K, Nr. 191). Vgl. Fiederlein, S. 124.

${ }^{203}$ Fiederlein, S. 124. 
angelegt, denn weder würde die Reichsregierung, die ihre ursprünglich „starke Position“ praktisch für „ein Linsengericht“ 204 aufgegeben hatte, auf die Dauer dem Druck des Reichspräsidenten, stärker Einfluß zu nehmen, widerstehen können, noch würden die östlichen Agrarier und ihre Vertreter, allen voran der nun tonangebende Hugenbergflügel der DNVP205, ruhen, mit allen Mitteln das Osthilfegesetz zu unterlaufen und die Arbeit der Preußenkasse zu erschweren.

Nach der Septemberwahl 1930, die einen deutlichen Rechtsruck gebracht und bei der auch die Osthilfe eine starke Rolle gespielt hatte, tauchten neue Pläne für eine umfassendere Osthilfe auf: das Hugenbergprogramm ${ }^{206}$ sowie der Entschuldungsplan von Friedrich Karl v. Zitzewitz-Kottow, den Klepper in einem für die Reichsregierung angefertigten umfangreichen Gutachten einer strengen Kritik unterzogen und der genau wie der Hugenbergplan „eine einmütige Ablehnung“ gefunden hatte. Außerdem gab es den im Dezember 1929 erstmalig vorgestellten Silverbergplan, der „in der Zeit der Krise“ „die Solidarität von Industrie und Landwirtschaft“ demonstrieren sollte, aber trotz des positiven Echos, das er ausgelöst hatte, keinen Niederschlag in der Osthilfe-Gesetzgebung vom Sommer 1930 gefunden hatte ${ }^{207}$. Sämtliche Pläne waren eine Antwort auf die trotz aller Maßnahmen wachsende Agrarkrise im Osten und führten schließlich zu dem Entschluß Brünings, Anfang Januar 1931 eine Ostreise zu unternehmen, um sein nicht nachlassendes Interesse an der Lösung des Agrarproblems zu demonstrieren. Brüning wollte versuchen, „die Diskrepanz zwischen der Wirklichkeit und der Überlegung am grünen Tissh für die nächste Zeit auszuschalten“, wie er in einer Rede in Ostpreußen versicherte ${ }^{208}$. Fiederlein meint, diese Ostreise habe „den Arbeiten zum Osthilfegesetz eine entscheidende Wendung “ gegeben ${ }^{209}$, da Brüning stark beeindruckt von der Not wie auch von der Rückständigkeit des Ostens zurückkehrte, den er „auch heute, nach 120 Jahren, nicht reif für eine Demokratie, auch nicht in gemäßigter Form, "hielt ${ }^{210}$. All diese Impulse führten zu den Bemühungen um eine neue Osthilfegesetzgebung, zu der erneut die Industrie hinzugezogen wurde ${ }^{211}$.

204 Denn Preußen hatte sich nicht, wie ursprünglich vom Reich erwartet, an der Finanzierung der Umschuldungsaktion beteiligt, vgl. Fiederlein, S. $125 \mathrm{ff}$.

${ }^{205}$ Am 19. Juli 1930 vollzog der von Kuno Graf v. Westarp geführte Flügel, dem auch Treviranus angehörte, die lang geplante Trennung von Hugenbergs DNVP und schloß sich am 23. 7. 1930 der Konservativen Volkspartei an, vgl. Fiederlein, S. 112 f. Vgl. die Rede des General-Landschaftsdirektors Walther v. Hippel am 28.1. 1931 in der Vollsitzung der Landwirtschaftskammer und den Begleitbrief von Regierungsassessor Emil Pahlke an Lauffer, 31. 1. 1931 (VNL-K, Nr. 191).

206 Der Wahlkampf wird von Fiederlein S. 127-147, vor allem aus der Perspektive Ostdeutschlands, genau dargelegt, die Ergebnisse werden analysiert, die Folgen erörtert, und ab S. $147 \mathrm{ff}$. die Reaktionen, die fast ausnahmslos negativ waren, erläutert.

207 Der Zitzewitzplan in: Umdruck, R 43/1805, Bl. 202-228, und Kleppers Gutachten vom 10. 12. 1930 ebenda, B1. 178-201, genau erläutert von Fiederlein, S. 154-159 und Silverbergplan, S. 159 f. Die Besprechung des Pläne zur Osthilfe siehe: Aufzeichnungen des Ministerialrats Feßler über eine Chefbesprechung wegen der Osthilfe 11. 12. 1930 (AdR-Brüning, Nr. 195).

${ }^{208}$ Die Reise dauerte vom 4. bis 11. Januar 1931. Text der Rede vom 6. 1. 1931 in: Treue, S. 263.

${ }^{209}$ Fiederlein, S. 160 ff., S. 160.

210 Brüning, Memoiren, S. 241 ff., S. 243.

${ }^{211}$ Am 30. 1. 1931 war ein auf dem Silverbergplan aufbauender neuer Entwurf von der Oststelle unter Mitwirkung des RFMs fertiggestellt worden (NL-Pünder, Nr. 111). Vgl. zu den folgenden Beratungen: Fiederlein, S. 166 f., Pünder, S. 88 und AdR-Brüning, Nr. 230 ff. 
Die Gesetzentwürfe, die Mitte Februar 1931 „nach undenklichen Schwierigkeiten“ vom Reichskabinett verabschiedet wurden, basierten weitgehend auf dem Gesetzentwurf vom Vorjahr ${ }^{212}$. Im Reichsrat hatte Preußen noch Änderungen durchsetzen können, die die Interessen der Preußenkasse gegenüber der Industriebank sicherstellten, was der Reichstag in seiner namentlichen Abstimmung am 26. März 1931 billigte ${ }^{213}$. Die drei Osthilfegesetze traten am 31. März in $\mathrm{Kraft}^{214}$, und gleichzeitig nahm der Reichstag auch das „Agrarermächtigungsgesetz“ ${ }^{215}$. Damit war "eine wichtige innenpolitische Aufgabe - die Verwirklichung der Osterbotschaft des Reichspräsidenten vom Vorjahr [...] zumindest was die gesetzgeberische Seite anbelangte, erledigt, [...] und Brünings innenpolitische Position [...] gestärkt" ${ }^{\text {216. }}$.

Nach dem Erlaß der drei Durchführungsverordnungen im Sommer ${ }^{217}$ hätte nun alles reibungslos ablaufen können; auch Preußen konnte zufrieden sein, denn das neu „festgelegte Entschuldungsverfahren entsprach fast vollständig den Vorstellungen Preußens“, aber gerade das war Anlaß genug für die Rechte, sich eben nicht zufriedenzugeben, sondern mit allen zur Verfügung stehenden Mitteln gegen das, rote‘ Preußen anzukämpfen, um so mehr, als sich nun die Weltwirtschaftskrise massiv auf Deutschland auszuwirken begann und das knapper werdende Geld natürlich auch das Osthilfebudget schmälerte. Preußen und vor allem die Preußenkasse und damit ihr Präsident blieben ein, rotes Tuch für den ostdeutschen Großgrundbesitz, und zwar nicht etwa wegen der Konstruktion des Osthilfegesetzes, sondern wegen der politischen Machtverhältnisse ${ }^{218}$.

Das Problem Osthilfe spitzte sich auf den Dualismus von Reich und Preußen zu. Bereits im Sommer 1930 war in den „Deutschen Führerbriefen“ die These vertreten worden, „daß bei einem Weiterbestehen des Dualismus von Reich und Preußen die Osthilfe zum Scheitern verurteilt und ohne Ausschalten der preußischen Regierung eine, Rettung der Landwirtschaft" nicht möglich sei“, ja daß "für den Fall eines Aufschiebens dieses Problems [...] , sich zwangsläufig die gesamte nationale Front einschließlich der Landwirtschaft mit dem Ziel der Durchsetzung des grundsätzlichen Kampfes' wieder zusammenschließen werde"219. Die Prophezeiung sollte nur allzu wahr werden. Ab Sommer 1931 ging es tatsächlich um einen „grundsätzlichen Kampf“, den Preußen am 20. Juli 1932 und das Reich am 30. Januar 1933 verlor. Klepper war sich dieser Gefahr bewußt, und sein Kampf um das agrarpolitische Konzept und um die Erhaltung Preußens muß vor diesem Hintergrund gesehen werden. Doch auch die Diffamierungskam-

212 Protokoll der Sitzung des Reichsministeriums vom 14. 2. 1931 in: NL-Pünder, Nr. 112 und Pünder, Tagebuchnotiz vom 16.2. 1931.

213 Verabschiedung durch Reichsrat und Reichstag, Gesetzestext, Fiederlein, S. $172 \mathrm{ff}$.

214 "Gesetz über Hilfsmaßnahmen für die notleidenden Gebiete des Ostens" (Osthilfegesetz; RGBl. 1931, I, S. 134 f.; abgedruckt bei Borcke-Stargordt, S. 117 ff., kommentiert S. 45 f.).

${ }^{215}$ RGBl. 1931, I, S. $101 \mathrm{f}$.

216 Fiederlein, S. 177. Vgl. RT, Bd. 445, S. 1987.

${ }^{217}$ RGBl. 1931, I: 21. 5. 1931 (S. 277), 29.6. 1931 (S. 355) und 22. 7.1931 (S. 397). Das Entschuldungsgebiet wurde erweitert, neue Landstellen wurden in Berlin, Rostock und Dresden errichtet, die Bestimmungen der bisherigen Umschuldungsrichtlinien an die neue Osthilfegesetzgebung angepaßt und Grundsätze für die zu bildenden Haftungsverbände erlassen (Fiederlein, S. $178 \mathrm{f}$.$) .$

${ }^{218}$ Fiederlein, S. 182 und 177, er zitiert den Grafen Westarp, RT, Bd. 445, S. 1987.

219 Fiederlein, S. 205, er zitiert die Deutschen Führerbriefe 3 (1930), Nr. 35. 
pagnen, die seinen Ruf nachhaltig geschädigt und Folgen bis in die Nachkriegszeit gehabt haben, gehören in diesen Kontext.

Das komplizierte Geflecht von Faktoren, die zum Ausbruch der Osthilfekrise geführt haben, und die Entwicklung bis zum Ausstieg Preußens aus der Osthilfe wird von Fiederlein so differenziert und durch reiches Quellenmaterial belegt dargestellt ${ }^{220}$, daß es hier genügt, noch einmal die Positionen der einzelnen Kontrahenten bei der Auseinandersetzung um die Durchführung der Osthilfe einander gegenüberzustellen, um deutlich zu machen, wie aus der Osthilfe der bereits anfangs skizzierte verschärfte Konflikt zwischen dem Reich und Preußen wurde, bei dem das schwächere Preußen den kürzeren zog. Braun schildert den Zusammenhang in seinen Memoiren: „Bei der Umschuldung bildete sich bald eine Begünstigung der Großgrundbesitzer zum Nachteil der bäuerlichen Besitzer heraus, was nicht zuletzt auf die Zusammensetzung der Taxkommissionen, die zumeist aus Interessenten bestanden, zurückzuführen war. Die preußische Regierung bemühte sich nicht ohne Erfolg, durch ihre örtlichen Behörden und die sachkundigen Kommissare der Preußenkasse diesem Unwesen entgegenzusteuern, wobei wieder der Dualismus Reich-Preußen in Erscheinung trat. Preußen sabotiert die Ostpreußenhilfe!, so schallte es durch die agrarkonservativen Blätter und fand auch seinen Widerhall im Reichspräsidentenpalais. Tatsächlich sabotierte Preußen nur den Mißbrauch dieser staatlichen Hilfsaktion zur Bereicherung der ostpreußischen Junkersippe. Diese versuchte, sich mit aller Gewalt durchzusetzen." 221

Braun skizziert die Konfliktparteien: Auf der einen Seite stand die Preußenkasse mit ihrer bereits beschriebenen politischen Zielsetzung, ihrem selbst von politischen Gegnern immer wieder anerkannten Know-how und ihrem großen Einfluß auf die Durchführung der gesetzlichen Bestimmungen. Die Preußenkasse war ihrerseits eingebettet in die Politik der hinter ihr stehenden Regierung unter Ministerpräsident Braun, und sie wurde in ihren Zielen und Maßnahmen bestätigt durch den neuesten Stand der Forschung auf dem Sektor der Wirtschafts- und Agrarpolitik. Man sollte meinen, eine gute und gefestigte Position!

Ihr gegenüber standen eine Vielzahl sich teilweise bekämpfender, teilweise stützender Personen beziehungsweise Institutionen, das heißt eine in sich uneinige Front: Einmal waren da die Großagrarier, vertreten zum Beispiel durch Graf Kalckreuth, den Präsidenten des Reichslandbundes, der im Juli 1931 in einem Brief an den Reichspräsidenten den Gedanken der Autarkie beschworen und zu einer Politik der "nationalen Opposition“, der "wertvollen“ und „fähigen Kräfte“ aufgerufen hatte, die „bereit seien, das Werk der Rettung Deutschlands verantwortlich zu übernehmen“ und den dazu notwendigen „völligen Bruch mit den Kräften des internationalen Marxismus“ zu vollziehen“222. Dem entsprach die Parole des bereits erwähnten Kommissars für die Osthilfe in Pommern, Johann Georg v. Dewitz: Die Landwirtschaft lehne die Politik der Preußenkasse ab und folglich müsse „der Dualismus zwischen Reich und Preußen“

\footnotetext{
${ }^{220}$ Fiederlein, S. 180-212.

${ }^{22 !}$ Braun, S. 386. Vgl. die übereinstimmende Schilderung bei Engelmann, S. 23.

${ }_{222} \mathrm{R} 43$ I/678, Bl. $132 \mathrm{ff}$,, Abschrift des Schreibens von Meissner, 24. 7. 1931, mit der Bitte um Kenntnisnahme an den RK übersandt, und mit dem Vermerk, der RP habe sich mit einer Empfangsbestätigung begnügt (Bl. 131), zitiert bei Fiederlein, S. 214.
} 
beseitigt werden ${ }^{223}$. Ein Teil dieser Gruppierung wollte, daß Preußen ganz im Reich aufgeht, ein anderer, und das war eher der größere Teil, wollte nur die ,rote' Regierung in Preußen beseitigen ${ }^{224}$. Zum anderen gab es den Reichspräsidenten, der seine Standesgenossen stützte ${ }^{225}$ und die Regierung Brüning seinerseits zunehmend unter Druck setzte. Schließlich Brüning selbst, der sich hinter Treviranus und zeitweilig gegen Preußen stellte. Noch vor der Verabschiedung des Osthilfegesetzes hatte er sich vorgenommen, „die erste Gelegenheit $[z u]$ benutzen, um Hirtsiefer - und Preußen überhaupt aus jedem Einfluß aus der Osthilfe herauszudrängen“, einmal um „der Sache“ willen, zum anderen „aus Rücksicht auf die politische Stellung von Treviranus“226. Allerdings konnte er dieses Vorhaben nicht gradlinig verfolgen, weil er seit den Septemberwahlen auf die Tolerierung der SPD angewiesen war und folglich Rücksicht auf die preußische Regierung nehmen mußte. Doch Klepper, den er für „eines der größten Hemmnisse für Treviranus bei einer schnelleren Durchführung der Ostpolitik“ hielt ${ }^{227}$, blieb Ziel zahlreicher Angriffe. Treviranus stützte diese Propaganda und verfolgte am eifrigsten die „Politik der Nadelstiche gegen Preußen, um dessen Austritt [aus der Osthilfe] zu provozieren“228.

Doch das Problem war, daß sich die Kritik der Landwirtschaft „nicht nur gegen Preußen und das Entschuldungssystem [richtete], sondern auch gegen Treviranus und Kurt Wachsmann, die Vertreter des Reiches in der Oststelle. Man sprach von der, Geschäftsunfähigkeit und Unzuverlässigkeit des, wenn auch menschlich sehr sympathischen Reichskommissars“. Man warf ihm eine „nur ungenügende Beherrschung dieser schwierigen Materie“ vor und kreidete ihm an, daß er sich „im Tageskampf gegenüber den preußischen Vertretern, die auf dem Gebiet des Agrarkreditwesens qualifizierte Kräfte waren“, als unterlegen und unfähig erwies, eine „einheitliche Linie in der Oststelle durchzusetzen und die Belange des Reiches energisch zu vertreten“229.

Für diese Uneinigkeit im konservativen Lager war die Preußenkasse und besonders Klepper der ideale Prügelknabe, wenigstens in der Abwehr konnte man sich einig sein. Eine ebenfalls zweifelhafte Einigkeit fand dieses Lager in der sogenannten „Harzburger Front “230. Welche grotesken Formen der Versuch, einzelne Persönlichkeiten bloßzustellen, annehmen konnte, beleuchtet die folgende, Klepper betreffende Anfrage im preußischen Landtag und der zugehörige Zeitungskommentar. Das Staatsministerium wurde von Hans v. Rohr gefragt, ob es das Verhalten Kleppers billige: er sei beim Genossen-

${ }^{223}$ Dewitz' Bericht vom 8. 5.1931 an Hindenburg (R 43 I/1809, Bl. 282-304) wird im Brief des RP an den RK vom 13. 5. 1931 erwähnt (AdR-Brüning, Nr. 297, Zitate aus dem Bericht in Anm. 1, ebenda).

${ }^{224}$ Fiederlein, S. $206 \mathrm{f}$.

225 In seinem Brief an Brüning vom 13. 5. 1931 stellte er sich hinter v. Dewitz und dessen Bericht, "der vieles bestätigt, was $[i \mathrm{hm}]$ auch von anderen Seiten wiederholt vorgetragen worden" sei und dessen Vorschläge zur Veränderung der Osthilfe er "durchaus beachtlich“ finde (AdR-Brüning, Nr. 297). Vgl. andererseits das sich allmählich verschlechternde Verhältnis Hindenburgs zu Braun (Schulze, Braun, S. 617 f.).

226 Brüning, Memoiren, S. 215. Dabei gilt es mitzubedenken, daß Treviranus eine sehr enge Verbindung zu Brüning hatte, laut Luther der einzige enge Freund, vgl. Luther, S. 129, Treviranus, Brüning und Ders., Exil.

227 Brüning, Memoiren, S. $481 \mathrm{f}$.

${ }^{228}$ Schulze, Braun, S. 686.

${ }^{229}$ Fiederlein, S. 211 f., er zitiert zahlreiche Zeitzeugen.

230 Bildung der Harzburger Front am 11. 10. 1931. Vgl. Bracher, Auflösung, S. $407 \mathrm{ff}$. 
schaftstag im November in Swinemünde, als die Versammlung sich zu Ehren des Generalfeldmarschalls August v. Mackensen erhoben habe, sitzen geblieben. Die Antwort des Staatsministeriums war: „Ja!" 231 Einige Tage später stand dazu folgender Kommentar in der Zeitung Der Tag: „Mit diesem kleinen Wörtchen ,ja“ wird die Berechtigung des nationalen Kampfes gegen das System in Preußen in geradezu klassischer Form bestätigt. Ein hoher preußischer Funktionär verweigert einem verdienten alten Soldaten die verdiente Ehrung. In jedem anderen Staat der Erde wäre ein solches Verhalten gerügt worden, in Neupreußen billigt es der Ministerpräsident. Dies ist eine politische Frage allerersten Ranges, wenn von Staats wegen Ehrfurcht nicht mehr die Rolle im öffentlichen Leben zugebilligt wird, die sie haben muß. Was soll die Reichswehr, der einfache Soldat denken, der auch in der Republik den Heerführern die nötige Achtung zu erweisen hat."232 Dies war die neue Art des Kampfes, dem die Verteidiger der Republik sich nun in zunehmenden Maße ausgesetzt sahen.

Zu diesem Zeitpunkt, am 23. November 1931, war es dann auch so weit, daß Preußen seine Vertreter aus der „Oststelle bei der Reichskanzlei“ zurückzog und folgende Mitteilung an die Presse gab: „Anläßlich des Erlasses der Notverordnung der Reichsregierung über die Umgestaltung der Osthilfe ${ }^{233}$ sind vielfach unzutreffende Mutmaßungen über die Behandlung der Landwirtschaftskredite seitens der preußischen Zentralgenossenschaftskasse aufgetaucht. In der allgemeinen Geschäftspolitik der Preußenkasse sind keine Änderungen eingetreten. Die Preußenkasse sieht nach wie vor ihre Aufgabe darin, Störungen im genossenschaftlichen Kreditapparat zu verhüten. Einerseits muß sie darauf dringen, daß fällige Rückzahlungen, soweit es irgend möglich ist, geleistet werden; deshalb lehnt sie generelle Stundungen ab. Andererseits wird sie da, wo die Rückzahlung unmöglich ist, jedes vertretbare Entgegenkommen zeigen." 234

231 GSTAM, Rep. 151 HB, Nr. 21, Bl. 30f., Antwort vom 21. 11. 1931. Vgl. BAP, 62 DAF3, 17632, Bl. 114: Frankfurter Zeitung, Nr. 875, 24. 11. 1931.

232 BAP, 62 DAF3, 17632, Bl. 115: Der Tag, Nr. 281, 24. 11. 1931: Dieser Vorgang und die Tatsache, daß die preußische Regierung nur mit "Ja“ geantwortet hatte, war auch Gegenstand der preußischen Landtagsdebatte vom 16. 12. 1931, die sich mit dem Mißtrauensvotum gegen Klepper als preußischer Finanzminister befaßte (PrLT, 264. Sitzung, Sp. 23170 ff., 23202 f.).

233 Erlaß des Reichspräsidenten „über die Bestellung eines Reichskommissars für die Osthilfe“ vom 5.11. 1931 (RGBl. 1931, I, S. 665), Notverordnung „zur Sicherung der Osthilfe“ vom 6.11. 1931 (ebenda), Verordnung „zur Änderung der Durchführungsverordnung zum Osthilfegesetz“ vom 14. 11. 1931 (RGBl. 1931, I, S. 681) und die Verordnung „zur Sicherung der Ernte und der landwirtschaftlichen Entschuldung im Osthilfegebiet“" vom 17. 11. 1931 (RGBl. 1931, I, S. 675), sind bei Borcke-Stargordt, S. 126 ff., abgedruckt.

${ }^{234}$ DGBkA, ND-P.Z., Nr. 273, 7. Jg., Bl. 2 vom 24. 11. 1931, ebenda Kommentare zum Osthilfegesetz von Korrespondenz Osthilfe und dem „Verband ostpreußischer Müller“. Vgl. dazu Brief Lauffers an Graf zu Castell-Rüdenhausen (Hamburg) vom 1. 10. 1956: „Im November 1931 entstanden zwischen der Reichsregierung und der preußischen Staatsregierung grundsätzliche Meinungsverschiedenheiten über die zweckmäßige Art, die Osthilfe fortzusetzen; insbesondere hatte die preußische Staatsregierung Bedenken, dem von der Reichsregierung geplanten generellen Vollstreckungsschutz zuzustimmen. Diese Meinungsverschiedenheiten führten dazu, daß Preußen im November 1931 seine Vertreter aus der Oststelle bei der Reichskanzlei - darunter auch mich - zurückzog" (Abschrift in K/Kor). 
Ab jetzt gab es nur noch einen Kommissar für Osthilfe, er hieß Hans Schlange-Schöningen ${ }^{235}$. Braun meint in seinen Memoiren, daß er "sich zum ernsten Politiker entwikkelt“ habe ${ }^{236}$ und "genau diejenige Politik“ betreibe, die er selbst „immer hatte durchsetzen wollen“, nämlich nicht mehr sanierungsfähige Betriebe „durch Siedlungsgesellschaften übernehmen und aufsiedeln“ zu lassen. Doch, so meint Hagen Schulze, war es gerade „diese Politik, die schließlich am übermächtigen Einfluß der agrarischen Interessenverbände auf den Reichspräsidenten zerschellen und zur Entlassung Brünings führen sollte“237. Übrigens hält Gerhard Schulz das agrarpolitische Programm Schlanges für „nicht sonderlich originell“238. Es sei vermutlich von Hirtsiefer übernommen worden, denn dessen Denkschrift über die „Durchführung der Osthilfe“ vom 21. Oktober $1931^{239}$ sei, noch bevor Brüning sie kannte, in die Hände Schlanges geraten und von diesem mit zustimmenden Kommentaren versehen worden ${ }^{240}$. Daß Hirtsiefers Denkschrift auf der Linie der Preußenkasse lag, ist naheliegend. Mochte Braun auch mit dem Kurs Schlanges zufrieden sein, so konnte ihn das „nicht dafür entschädigen, daß eine seit 1918 mühsam gegen das Reich errichtete Position Preußens mit einem Schlage zusammengebrochen war" ${ }^{241}$. Auch Klepper empfand dies, wie Engelmann zu berichten weiß, als eine „Niederlage seiner Politik“242.

Auf die Frage, warum Schlange, der im Endeffekt genauso scheitern mußte wie Klepper, zunächst erfolgreicher war, lassen sich mehrere Antworten finden. Vor allem konnte er von dem Jubel darüber, daß die ,roten'Preußen endlich aus der Osthilfe heraus waren, profitieren. Außerdem war Schlange Landwirt, Standesgenosse und kam aus dem Osten, nichts davon traf auf Klepper zu. Schlange hatte nicht nur eine etwas geschicktere Art, seine Ideen zu vermitteln, sondern er setzte auch andere Akzente, die Erhaltung der Be-

${ }^{235}$ Schlange-Schöningen wurde am 9. 11. 1931 Reichsminister ohne Geschäftsbereich und Reichskommissar für die Osthilfe (vgl. Schlange-Schöningen, Am Tage, S. 53 und zur Vorgeschichte S. $50 \mathrm{ff}$.). Schlange erhielt auf Anregung Aereboes den landwirtschaftlichen Ehrendoktor (Muth, Zum Sturze, S. 748). Wengst, in: GWU 30 (1979), S. 538-551.

236 Braun, S. 389. Vgl. auch das Urteil Grzesinskis: Er bezeichnet Schlange-Schöningen als „aufgeklärten und deshalb im Rechtslager so sehr verhaßten Junker“ (Lebensweg, Bl. 275). Schlange schreibt in seiner Schrift „Bauer und Boden“ über Tiberius Gracchus, wohl sich selbst skizzierend: „Ganz selbständig geworden, machte er die große, in Rom noch nie dagewesene Kehrtwendung vom Optimatenkrieger zum sozialen Politiker, zum Anwalt der Armen“ (S. 7). Vgl. auch das Schlange-Kapitel bei Fiederlein, S. 216 ff., Muth, Zum Sturze, S. 741 ff., Muth, Agrarpolitik, S. $323 \mathrm{ff}$. Im November 1927 hatte Schlange-Schöningen schon eine Broschüre: „Die Rettung der Landwirtschaft, ein Gesetzesvorschlag zur Neuregelung des landwirtschaftlichen Kredites", veröffentlicht (GSTAB, Rep. 84a, 1911, Bl. 33-42).

${ }^{237}$ Schulze, Braun, S. 688.

${ }^{238}$ Schulz, Brüning, S. 593: „Schlange war nicht sonderlich originell, was Muth verkennt. Er bedurfte der Anregungen und war offenkundig durch intellektuell beweglichere Köpfe beeinflußbar."

${ }^{239}$ Ebenda, S. 592. Die Denkschrift befindet sich in: GStAB, Rep. 90, Nr. 1111, abgedruckt in: Politik und Wirtschaft, S. 1067-1071. Hirtsiefer hat sie zum Abschluß seiner Tätigkeit als Kommissar für die Osthilfe verfaßt, und man kann mit Sicherheit annehmen, daß er die Abfassung mit Klepper zumindest beraten hat, zumal sich starke Parallelen zu Kleppers Aufsätzen und seiner Schrift über die Auffangorganisationen (s.o.) nachweisen lassen. Vgl. ebenda, S. 1072 ff.: „Aufzeichnungen Schlange-Schöningens zur Agrarpolitik" vom 24. 10. 1931.

${ }^{240}$ Schulz, Brüning, S. 592. Am 29. 10. 1931 hat Braun die Schrift an Brüning gesandt.

${ }^{241}$ Schulze, Braun, S. 688.

242 Engelmann, S. $24 \mathrm{f}$. 
triebe war oberstes Gebot, und durch sein neues Sanierungsverfahren ${ }^{243}$ gewährte er fast allen verschuldeten Betrieben zunächst einmal eine Atempause und vorübergehenden Schutz vor der Zwangsvollstreckung. Trotz scharfer Gegenreaktionen, die auch er erfuhr ${ }^{244}$, besaß Schlange die Vollmachten des Reichspräsidenten, konnte die Ostbehörde in einer Hand konzentrieren und sich auf einen eingespielten und gut geschulten Beraterstab stützen, der, von Klepper angespornt, loyal unter der neuen Führung weiterarbeitete.

Was das für die Berater im einzelnen bedeutete, geht aus ciner von Engelmann geschilderten Besprechung Kleppers mit seinen erfahrensten Betriebsstellenleitern wenige Monate nach der Neuregelung hervor. Diese übten teilweise in scharfer Form Kritik an der neuen Durchführung der Osthilfe, Klepper habe sich alles ruhig, „zunächst ohne Kommentar, aber sichtlich zustimmend und über manche Bemerkung seiner früheren, jetzt einer Reichsbehörde unterstellten Mitarbeiter belustigt“, angehört. Doch dann habe er sich zu einer Schlußbemerkung erhoben, allen Referenten gedankt, „sein Verständnis für ihre Schwierigkeiten, einer den früheren Intentionen, in denen sie geschult waren, entgegengesetzten agrarpolitischen Aktion dienen zu müssen“, zum Ausdruck gebracht und „mit erhobener Stimme - ein von ihm höchst selten angewandtes rhetorisches Mittel hinzu[gefügt], , aber es wird weitergearbeitet, und zwar loyal und seriös“"245. Die Tatsache, daß das von Klepper geschulte Personal weiter für die Arbeit der Osthilfe zur Verfügung stand, hat entscheidend zu den Anfangserfolgen von Schlanges Ostpolitik beigetragen. Auch gab es gewisse Parallelen zwischen Klepper und Schlange in ihrer Arbeitsweise. Beide organisierten ihre Ämter unkonventionell, rationell und auf Teamarbeit und Eigenverantwortlichkeit ausgerichtet ${ }^{246}$. Sie scheinen sich im Kreis von Professor Ernst Jaeckh, dem Gründer und Präsidenten der Deutschen Hochschule für Politik, begegnet zu sein ${ }^{247}$. Auch Schlange wurde als "Agrarbolschewist“ ${ }^{248}$ und von seinen eigenen Leuten (DNVP) als „Hecht im Karpfenteich“ bezeichnet ${ }^{249}$. Sogar Brüning sah beide im Zusammenhang; in einem Briefentwurf an Rudolf Olden schrieb er 1935: „Ich freue mich, daß Sie wenigstens an Schlange etwas Gutes finden. Er ist der einzige, der später die Agrarfragen lösen kann. Wenn Klepper gelernt hat, seine Regungen zum Quertreiben zu unterdrücken, wird seine außergewöhnliche Intelligenz neben Schlange das Wertvollste sein." 250

Für Klepper endete das Kapitel Osthilfe im November 1931, etwa gleichzeitig mit seiner Tätigkeit als Präsident der Preußenkasse. Daß er sich als solcher trotz aller Polemik unbestrittene Verdienste um die Stabilisierung der Bank, die als eine der wenigen in der

${ }^{243}$ Vgl. Schulz, Brüning, S. 595. Schulz nennt das Sanierungsverfahren „eine neue Rechtsfigur. Die Betriebe beantragten beim Leiter des zuständigen Finanzamtes die Zulassung zum Sanierungsverfahren; dieser entschied nach Anhörung landwirtschaftlicher Sachverständiger", wobei Schlange betont, daß „äußerstes Wohlwollen““ zu herrschen habc.

${ }^{244}$ Braun, S. 390.

245 Engelmann, S. $24 \mathrm{f}$.

246 Schlange, Am Tage, S. $54 \mathrm{ff}$.

${ }^{247}$ BAK, NL-Schlange-Schöningen, Politische Papiere Nr. 2. Vgl. Fiederlein, S. 217.

${ }^{248}$ Vgl. Muth, Agrarpolitik, S. 327-331, S. 338 ff., 350 ff., vgl. vor allem S. 360: der Anteil von Schlanges Agrarpolitik am Sturz Brünings.

${ }^{249}$ BAP; Akte DNVP 60V² (9), Bl. 103: Oscar Hergt an Erich Rogge, 27. 10. 1923, ebenda, Bl. 85: Schlange an Hergt, 3. 12. 1923.

250 Brüning, Briefe, S. 85, Brief vom 28. 8. 1935. 
Bankenkrise vom Sommer 1931 liquide blieb251, sowie um die Reorganisation des Genossenschaftswesens, das „ohne ihre vorangegangene Erstarkung und Konsolidierung [...] als geschlossene Organisation“ die Zeit des Nationalsozialismus „schwerlich überstanden" hätte ${ }^{252}$, erworben hat, ist selbst bei seinen Gegnern unbestritten. Um so erstaunlicher ist es, daß er seinen durch Ansehen gefestigten und gut bezahlten Posten mit dem vergleichsweise schlecht dotierten Schleudersitz ${ }^{253}$ des preußischen Finanzministers zu vertauschen bereit war.

251 „Preußen 1932“, S. 106: „Die katastrophale Krise im Jahre 1931, der sogar bedeutende Großbanken zum Opfer fielen, wurde von der Preußenkasse ohne fremde Hilfe (Staatsstützung) überwunden.“

252 Engelmann, S. 33.

253 Kleine Anfrage, Nr. 2938, des DNVP-Abgeordneten v. Rohr im PrLT, 17. 11. 1931: „Herr Klepper erhielt in seiner alten Stellung ein Jahresgehalt von 100000 RM, während die Gesamtbezüge in seiner neuen Stellung sich auf nur etwa 30000 RM belaufen. Auf den Erwerb einer Pensionsberechtigung in der neuen Stellung ist nicht zu rechnen, da der neu zu wählende Landtag zweifellos einen Mann wie Herrn Klepper nicht im Amt lassen wird. Auch die Rückkehr in seine alte Stellung wird ihm verschlossen sein. Infolgedessen bedeutet der Wechsel aus dem alten in das neue Amt für Herrn Klepper äußerlich eine erhebliche finanzielle Schlechterstellung. Es wird daher in weiten Kreisen befürchtet, daß Herr Klepper unter der Hand ein Ersatz für die äußerlich eingetretene Gehaltsminderung verschafft oder zugesichert worden ist. Ich frage das Staatsministerium: 1. Erhält Herr Klepper als Finanzminister außer dem im Haushalt verzeichneten Betrage noch irgendwelche Zuwendungen aus Mitteln des preußischen Staates, der Preußenkasse oder irgendwelcher anderen in unmittelbarer oder mittelbarer Beziehung zum preußischen Staat stehenden Stelle? 2. Sind Herrn Klepper im Zusammenhang mit seiner Berufung irgendwelche anderen Zuwendungen oder Zusicherungen seitens des Herrn preußischen Ministerpräsidenten gemacht oder vermittelt worden?" (GSTAM, Rep. $151 \mathrm{HB}, \mathrm{Nr}$. 21, Bl. 27 ff.) Die Antwort erfolgte am 21.30. 1931 mit „Nein“, gez. Braun. Dazu gehört ein Brief Brauns an den Chefredakteur Fischer von Der Vorstoß vom 21. 11. 1931, in dem genaue Angaben über den Verdienst Kleppers gemacht werden (75 000 RM bei der P.Z. und ca. $28000 \mathrm{RM}$ als FM ohne besondere Zusicherungen). Dazu: DGBkA, ND-P.Z., Nr. 270, 7. Jg., Bl. 2 f., 20. 11. 1931. Am 19. 11. 1931 erfolgte eine zweite Anfrage (Nr. 2943) in der gleichen Angelegenheit durch den NSDAP-Abgeordneten Wilhelm Kube (GSTAM, Rep. $151 \mathrm{HB}, \mathrm{Nr}$ 21, Bl. 32). Gemäß seiner Gehaltsaufstellung in VNL-K, Nr. 154, Bl. 55 (1931) erhielt Klepper monatlich: Dienstbezüge als Minister 3000 RM Grundgehalt, 210 RM Wohnungszuschuß, 55 RM Kinderbeihilfe, 90 RM Ortszuschlag, 400 RM Aufwandsentschädigung minus 136 RM Steuer, dazu kamen Nebeneinnahmen jährlich berechnet: Deutsche Rentenbank-Kreditanstalt 2600 RM, Deutsche Genossenschaftshypothekenbank 513,64 RM, Deutsche Landesbankzentrale 1000 RM, GetreideHandelsgesellschaft 1890 RM, Hannoversche Bodenkreditbank 1408,70 RM, Getreideindustrie- und Commissions AG 2000 RM, zusammen: 9412,34 RM jährlich (monatlich etwa $785 \mathrm{RM})$. 